\title{
Avanços metodológicos na determinação do consumo de ruminantes em pastejo
}

\author{
Paulo César de Faccio Carvalho', Gilberto Vilmar Kozloski², \\ Henrique Mendonça Nunes Ribeiro Filho ${ }^{3}$, Mônica Vizzotto Reffatti ${ }^{4}$, \\ Teresa Cristina Moraes Genro ${ }^{5}$, Valéria Pacheco Batista Euclides ${ }^{6}$
}

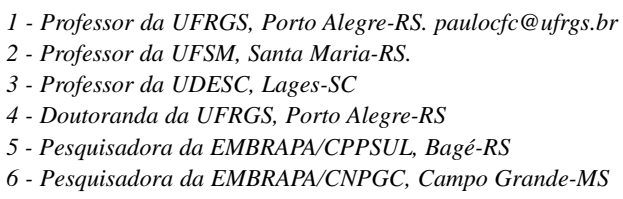

RESUMO - Avanços metodológicos são, usualmente, conseqüência direta de avanços conceituais e tecnológicos. No caso da estimativa do consumo em pastejo, os recentes avanços conceituais relativos ao processo de busca e apreensão da forragem pelo ruminante evidenciaram a importância da unidade básica do consumo - o bocado -, e dos fatores limitantes ao consumo que ocorrem antes da ingestão da forragem pelo animal em pastejo. A abordagem reducionista do processo de pastejo, aliada à sua hierarquização espaço-temporal, trouxeram uma nova concepção de como o animal obtém o seu alimento do pasto. Destes modelos conceituais emergiram novas variáveis que requerem novos procedimentos experimentais e analíticos. Neste contexto, importantes avanços têm ocorrido. Este artigo apresenta e discute os novos procedimentos que permitem estimar o consumo no curto prazo, assim como aqueles mais utilizados pela comunidade científica nacional para estimar o consumo no longo prazo. Adicionalmente, são feitas também considerações sobre o uso de animais ou de piquetes como unidades experimentais em experimentos de pastejo. Conclui-se que, apesar de ainda existir importantes barreiras metodológicas, os recentes avanços conceituais sobre o processo de pastejo, assim como dos procedimentos analíticos, geram fortes expectativas de avanço em curto e médio prazo na obtenção de estimativas qualificadas de consumo por animais em pastejo.

Palavras chave: alcanos, bocado, estrutura do pasto, ingestão, óxido de cromo

\section{Advances in methods for determining animal intake on pasture}

\footnotetext{
ABSTRACT - Methodological advances are usually a direct consequence of conceptual and technical advances. In the case of animal intake on pasture, recent conceptual advances regarding the process of searching and apprehension of the forage by the ruminant provide insight regarding the importance of the basic unit of intake, the bite, and the importance of processes limiting intake that occur before the forage reaches the rumen. Applying a reductionist approach to the grazing process, along with its spatial-temporal hierarchy, brought a new conceptualization of how an animal obtains feed from pasture. From the conceptual models emerged new variables that required new experimental and analytical procedures. Within this context, important advances have occurred. This article describes the new procedures that allow to estimate the consumption on the short-term, as well as that most utilized by the national scientific community for estimating the consumption on the long-term. Procedure for estimating fecal production and digestibility are discussed, as well as the use of n-alkanes and other emerging techniques. Consideration is given to the use of animals or paddocks as experimental units in grazing experiments. The conclusions presented in this article do not differ from those of preceding articles regarding this subject. In a grazing condition, continuous intake is the "black box" to be revealed, complex by nature with regard to the animal as well as the pasture, and there are important methodological barriers toward is determination. Nevertheless, recent advances in conceptualizing the grazind process, as well as in the analytical procedures, have been considerable and generate ambitious expectations over the short and long term.
}

Key Words: alkanes, bite size, chromic oxide, intake, pasture structure 


\section{Introdução}

O consumo de forragem é o principal fator determinante do desempenho de animais em pastejo, é influenciado por vários fatores associados ao animal, ao pasto, ao ambiente e às suas interações. $\mathrm{O}$ consumo pelos animais a pasto, no entanto, não pode ser determinado diretamente, de modo que várias metodologias foram desenvolvidas para estimá-lo. Os aspectos centrais que têm caracterizado a trajetória da pesquisa, e que construe o atual estado-da-arte dos procedimentos para estimativa do consumo em pastejo, são apresentados na Tabela 1 como uma seqüência de considerações da comunidade científica ao longo das últimas décadas.

Embora as afirmações apresentadas pelos diferentes autores tenham sido feitas com base no contexto original de seus trabalhos e de sua época, é evidente, e mesmo surpreendente, a natureza similar das suas afirmações. Mesmo que os procedimentos experimentais e analíticos tenham evoluído ao longo do tempo, as estimativas do consumo em pastejo ainda continuam sendo deficientes em acurácia e confiabilidade.

Por ocasião da segunda edição do livro Herbage Intake Handbook (2004), John Hodgson indaga: "Quais mudanças ocorreram nos últimos 20 anos, desde a publicação da primeira edição, que afetaram a escolha dos procedimentos de determinação do consumo e de seleção de dietas?". Segundo ele, quatro são os avanços de maior relevância:

i) o desenvolvimento de automação no registro automático das atividades de pastejo que facilitam a flexibilidade, a continuidade e o detalhamento da coleta de dados e os procedimentos de processamento da informação;

ii) desenvolvimento de tecnologia para uso cada vez maior de micro-constituintes de planta para uso como marcadores quantitativos, trazendo flexibilidade de escolha no manejo e monitoramento dos animais;

iii) a restrição cada vez maior ao uso de animais preparados cirurgicamente, como resultado de preocupações crescentes com ética e bem-estar dos animais; $\mathrm{e}$

iv) reconhecimento progressivo de interesses comuns entre a ecologia e a produção animal.

Da mesma forma, Penning (1998) listou os tópicos mais discutidos desde 1974 pelo grupo de cientistas europeus envolvidos com a temática de determinação de consumo em condições de pastejo, e concluiu que o uso de novos marcadores, como os alcanos, e os pregressos na automação dos registros do comportamento ingestivo dos animais, representaram avanços importantes na compreensão do processo de pastejo.

Em sinergia com esses avanços, a compreensão dos fenômenos envolvidos no processo de seleção e aquisição da forragem pelos ruminantes em pastejo evoluiu consideravelmente nos últimos 20 anos. Grande contribuição teve a área de Ecologia, cujo interesse no processo de alimentação dos ruminantes trouxe ao ambiente científico da Zootecnia uma nova amplitude de hipóteses e teorias a serem testadas, tais como aquelas ligadas ao processo evolutivo (e.g., Teoria do Forrageamento Ótimo) e à hierarquização espaçotemporal do processo de pastejo (Senft et al., 1987). Outra abordagem que acarretou grandes avanços foi a aplicação do reducionismo na elucidação dos processos envolvidos no pastejo (Laca \& Demment, 1992), que definiu o "átomo do pastejo" como sendo o bocado.

A conseqüência destes novos conceitos foi o surgimento de novos parâmetros de avaliação e, consequentemente, de novas técnicas e procedimentos analíticos, bem como de novos modelos matemáticos (vide Baumont et al., 2004 e Pittrof \& Soca, 2006). Com isto, houve um enorme avanço no conhecimento dos fatores que afetam o consumo em pastejo, particularmente no curto prazo, com destaque para aqueles associados à estrutura do pasto (Carvalho et al., 2001) e à regulação metabólica (Provenza et al., 2007).

Neste contexto, este trabalho tem por objetivo apresentar e discutir os novos conceitos e procedimentos para estimar consumo a pasto, particularmente aqueles associados à ingestão no curto prazo, mas também discute e apresenta novas proposições sobre os procedimentos tradicionais e de uso mais corrente pela comunidade científica nacional para estimar o consumo diário de pasto pelos animais.

\section{Avanços conceituais no processo de consumo em pastejo}

Laca \& Demment (1992) propuseram a divisão do processo de ingestão de animais em situação 
Tabela 1 - Considerações sobre a estimativa do consumo em condições de pastejo numa perspectiva histórica

\begin{tabular}{cl}
\hline Ano & Afirmação $^{1}$ \\
\hline 1962 & $\begin{array}{l}\text {... because of this it is practically impossible to sample forage manually } \\
\text { and get forage similar to that selected by the grazing animal. Therefore, } \\
\text {...the chemical composition of forage, the digestibility of forage } \\
\text { constituents, and the intake of forage must be measured indirectly. }\end{array}$ \\
1969 & $\begin{array}{l}\text { Accurate intake estimates are difficult to achieve... } \\
1970 \\
\text { What may be even more difficult is the selection of a sample } \\
\text { representative of that normally consumed by the animal. } \\
\text { That many intake studies continue to be made indicates it is recognized } \\
\text { the work is important and must not be avoided because of practical } \\
\text { difficulties; the reports generally indicate awareness of the various } \\
\text { technical problems. }\end{array}$
\end{tabular}

1982 The approach to intake measurements followed in this chapter cautious, critical and even pessimistic - has been chosen deliberately to encourage the reader to take an equally critical view.

1989 A number of authors discussed the advantages and disadvantages of methods for measuring forage intake of grazing animals, none of which were completely satisfactory.

1992 Considering that there are multiple factors affecting consumption under grazing conditions, it is not surprising that its prediction by simple laboratory methods is inconsistent.

1994 A method that adequately estimates dry matter intake of grazing animals remains essential to fully utilize the value of pasture research but continues to be elusive... Estimating the forage intake of free grazing animals is so difficult that all of the commonly used methods have limitations and consist of various compromises that may introduce error.

1995 There is no "best" technique for making measurements. The most appropriate technique will depend upon the goals of the research and the circumstances under which the measurements are made including such considerations as the time scale of the study, grain of heterogeneity, the availability of tame animals, logistics and funding.

1997 La estimación de consumo en pastoreo es tan compleja que todos los métodos comúnmente usados tienen limitaciones y implican un compromiso que puede introducir errores. Mientras ninguna de las técnicas es totalmente adecuada, cada una tiene valores en situaciones particulares...

1998 This is a problem which is more prevalent in sward than animal aspects of integrated intake studies, due in the main to the widely different nature of the populations (plant or animal) to be sampled.

2000 Determinations of intake and diet composition in free-ranging herbivores are generally difficult to undertake, and their errors are often large, mainly owing to the limitations of available measurement techniques.

2004 The authors repeatedly stress that there is no single best method for measuring herbage intake.

2005 While several lifetimes have been devoted to developing techniques to "measure" intake and diet quality, they are laborious, expensive, and often lack both precision and accuracy

2006 Todos os indicadores possuem limitações. A escolha de um indicador deve ser baseada na sua taxa de recuperação fecal, validada em ensaios de coleta total de fezes, e associada a outras características desejáveis para este fim.

2007 Outro ponto importante é também poder inferir sobre qual equação funciona satisfatoriamente, uma vez que os consumos estimados através de modelos e com o uso de indicadores não apresentaram resultados que possibilite (sic.) maior confiabilidade...

Pidgen \& Minson (1969)

Johnson (1970)

Corbett (1980)

Greenhalgh (1982)

(Stuedemann \& Matches, 1989)

Lascano (1992)

Burns et al. (1994)

Gordon (1995)

Astigarraga (1997)

Laidlaw (1998)

Mayes \& Dove (2000)

Wilkins (2004)

Coleman (2005)

Rodrigues et al. (2006)

Berchielli et al. (2007)

${ }^{1}$ Afirmações mantidas na língua original com o intuito não comprometer sua propriedade.

๑ 2007 Sociedade Brasileira de Zootecnia 
de pastejo em pelo menos duas escalas temporais: curto e longo prazo. No curto prazo, numa escala de minutos a horas de pastejo, o consumo de forragem é resultado da estrutura e acessibilidade do pasto, bem como de sua abundância e qualidade. Nesta escala, o processo é denominado velocidade de ingestão ou taxa de consumo, sendo expressa em g de matéria seca (MS) ingerida por minuto de pastejo. Os principais mecanismos que atuam nessa escala são aqueles relacionados à colheita e à manipulação da forragem pela ação do pastejo, onde a massa do bocado é o parâmetro mais determinante da ingestão e a estrutura do pasto atua com mais evidência (Carvalho et al., 2001).

No longo prazo, a resposta funcional é comumente denominada de consumo diário, sendo expressa em $\mathrm{kg}$ de MS por dia e medido em escalas que vão de dias a semanas. Os fatores que controlam o consumo, neste caso, passam a ser focalizados nos processos digestivos, onde a taxa de passagem e a capacidade gastrointestinal assumem importância, ao lado de outros parâmetros de natureza não nutricional, como a termorregulação, a necessidade de socialização, descanso e requerimentos de água, bem como de vigilância (Laca \& Demment, 1992).

Obviamente, ambas as escalas não são de natureza independente, embora signifiquem processos distintos. O consumo diário é um produto da taxa de ingestão e pode ser visto como um processo cumulativo oriundo do somatório dos bocados colhidos no pasto ao longo de um tempo determinado (Carvalho \& Moraes, 2005). A origem de base dessa proposição está no trabalho de Allden \& Whittaker (1970), que propuseram que o consumo diário de uma animal em pastejo seria produto do tempo de pastejo pela taxa de bocados. Este conceito foi aperfeiçoado por Rook (2000) que propôs o consumo como sendo o produto da massa do bocado (MB), da taxa de bocado (TB), do tempo de duração das refeições (DR) e do número de refeições (NR) ao longo do dia, onde:

\section{$C=(M B \times T B) \times(D R \times N R)$}

Kyriazakis (2003) considera que, embora não claramente explícito, o conceito atualmente dominante é que os mecanismos que regulam o consumo de curto e longo prazo são os mesmos e, portanto, o controle acontece dentro das refeições e entre refeições ao longo do dia, coordenando períodos de atividade de ingestão e ruminação. Em consonância com esta proposição, Carvalho et al. (2005) apresentaram um modelo conceitual que propõe uma relação entre o comportamento ingestivo de curto prazo, dentro de uma refeição e entre refeições, e o consumo de longo prazo (Figura 1).

Sempre há uma motivação para o início de uma refeição, normalmente mediada pelo esvaziamento do trato gastrointestinal e pela demanda do animal por saciedade (Provenza et al., 2007). Há outros tipos de estímulo, do tipo troca de piquete, ou aquele que ocorre após uma ordenha, dentre outros, os quais fazem com que uma refeição se inicie. O consumo cumulativo é elevado no início, mas vai diminuindo no decorrer da refeição. Com o passar do tempo, após o início da refeição, vai ocorrendo o enchimento ruminal e a exaustão física dos animais, aumentando o número de intervalos intra-refeições (Gibb, 1998). Adicionalmente, aumentam os estímulos pós-ingestivos de saciedade (Crancio \& Carvalho, 2007). O consumo cumulativo dentro da refeição é, portanto, uma "função de aceleração-negativa" em relação ao tempo, tal como previsto por Penning (2004). A refeição termina quando os animais atingem um determinado nível de ingestão, iniciando-se um intervalo inter-refeição que permite a ruminação, descanso e outras atividades (Carvalho, 1997) até o início de um novo ciclo. O consumo de longo prazo em situação de pastejo é, então, o produto cumulativo da ingestão obtida em cada uma das refeições ao longo do dia. As características das refeições (duração, número, distribuição ao longo do dia, etc.) e a magnitude do consumo obtido são reflexos diretos da qualidade, quantidade e estrutura do pasto que se oferece ao animal (Carvalho \& Moraes, 2005).

\section{Avanços e considerações sobre a determinação dos componentes do consumo: comportamento ingestivo e consumo de curto prazo}

Com base na proposição de que o tempo de pastejo seja um dos parâmetros que definem o

๑ 2007 Sociedade Brasileira de Zootecnia 


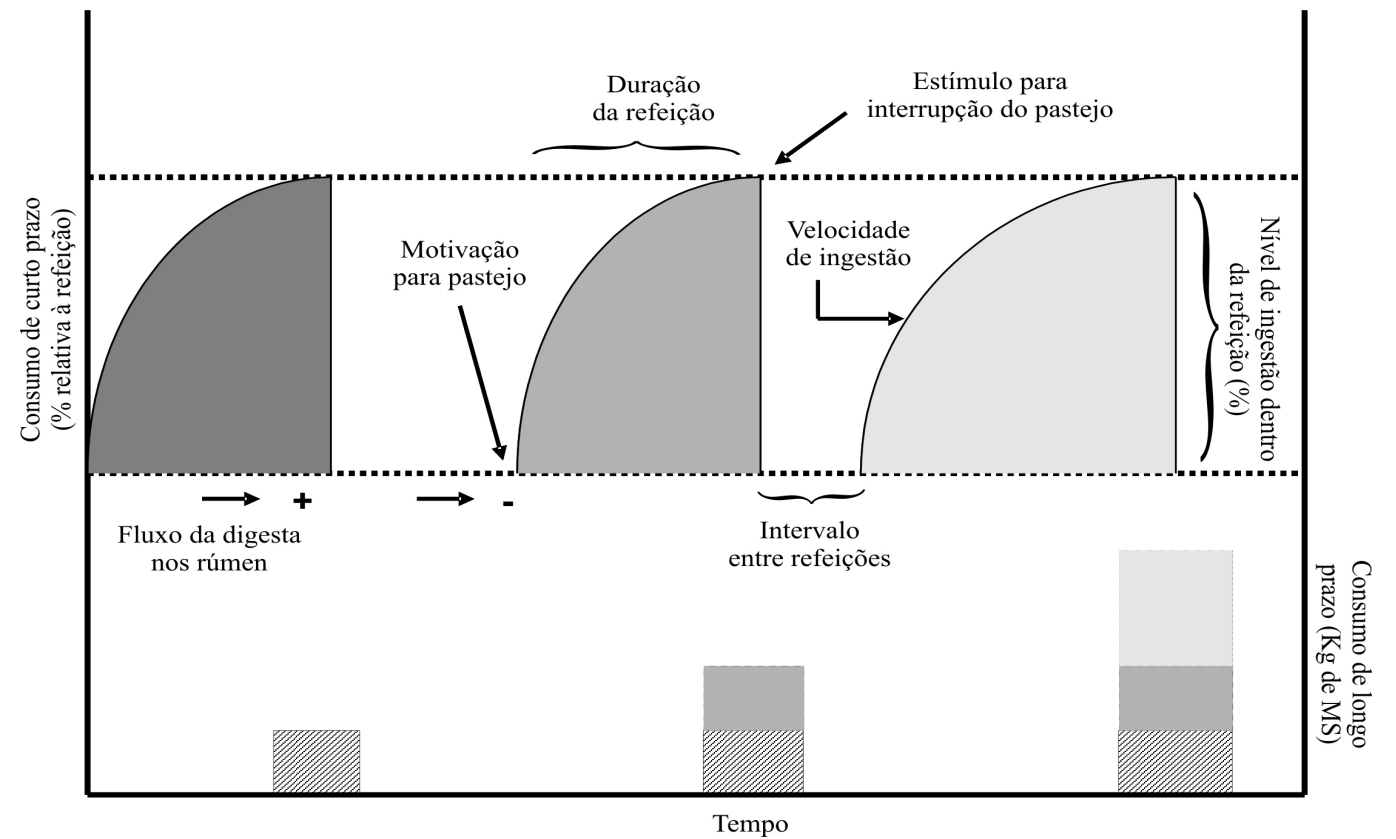

Figura 1 - Modelo conceitual de como o consumo de longo prazo, em situação de pastejo, é o resultado do somatório de ciclos de pastejo de curto prazo denominados refeições (adaptado de Carvalho et al., 2005).

consumo dos animais, tem-se verificado um incremento considerável de publicações nacionais que determinam esta variável em seus protocolos experimentais. Segundo Penning (2004), quando não se faz uso de registros automáticos das atividades dos animais, a observação visual das mesmas em intervalos de 5 a 10 minutos permite atingir níveis adequados de acurácia. Além das atividades de pastejo em si, esta técnica permite monitorar também outras atividades, como ruminação, procura por água e sal, entre outras, as quais têm sido incorretamente denominadas de ócio (vide definição de "outras atividades" em Pinto et al., 2007). É desejável que as observações sejam feitas ao longo de 24 horas. Porém, quando o tempo de pastejo é a variável de maior interesse, e dependendo da estação do ano, observações diurnas podem ser suficientemente representativas. Carvalho et al. (não publicado) observaram que o pastejo diurno representou mais de $90 \%$ do tempo total de pastejo por ovinos em azevém.

Gibb (1998) destacou a importância de distinguir a diferença entre tempo de pastejo, e tempo de alimentação. Tempo de alimentação é definido como sendo o tempo de pastejo menos os intervalos intra-refeições e seria um parâmetro mais adequado para calcular o consumo. Esses intervalos, contudo, dificilmente são observados por procedimentos visuais (Penning, 2004).
A taxa de bocados é, usualmente, observada em diferentes períodos do dia, registrando-se o tempo necessário à ocorrência de um prédeterminado número de bocados. Penning \& Rutter (2004) sugerem o registro de 100 a 300 bocados por períodos de 1 a 3 minutos, repetidos ao longo do dia, uma vez que os procedimentos realizados em períodos menores, tais como o tempo para realização de 20 bocados, tendem a gerar valores superestimados em até $16 \%$.

A massa do bocado, por sua vez, tem sido determinada por procedimentos que utilizam animais fistulados no esôfago (e.g., Trindade, 2007). Neste caso, a coleta da extrusa e o monitoramento da taxa de bocados devem ser feitos simultaneamente. O uso desta técnica é limitado pela necessidade de se ter animais preparados cirurgicamente e pela possível mudança do comportamento ingestivo desses animais. Além disso, por se tratar de uma informação quantitativa, diferente do uso de animais fistulados para determinação da natureza da dieta selecionada, não pode haver perda de material deglutido, o que não é fácil de assegurar (Gordon, 1995). A massa do bocado também pode ser estimada com base na determinação direta da taxa de ingestão associada ao monitoramento da taxa de bocados (e.g., Silva et al., 2007). Isto pode ser feito pela técnica da dupla pesagem dos animais, antes e após pastejo, utilizando-se

๑ 2007 Sociedade Brasileira de Zootecnia 
balanças de alta precisão. O uso desta técnica tem aumentado devido à legislação existente nos países desenvolvidos que restringe o uso de animais cirurgicamente preparados em pesquisa (Penning \& Rutter, 2004). Por esta técnica o consumo é calculado como:

$$
\mathbf{C}=\left(\mathbf{P} \mathbf{t}_{2}+\mathbf{F}+\mathbf{U}+\mathbf{P M}\right)-\mathbf{P t _ { 1 }}
$$

onde $\mathrm{Pt}_{1}$ e $\mathrm{Pt}_{2}$ são os pesos dos animais antes e depois do pastejo, F são as fezes, U a urina, e PM a quantificação da perda de peso metabólica. A produção fecal e urinária dos animais pode ser obtida pelo uso de bolsas coletoras (Silva et al., 2007). A perda de peso metabólica, que representa as perdas de peso do animal durante o pastejo devido à

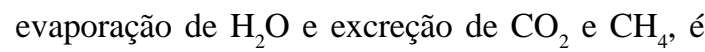
medida como perda de peso do animal em jejum em período anterior ou posterior à entrada dos animais na pastagem. Penning \& Rutter (2004) sugerem que, para estimar consumo com esta técnica, as atividades dos animais deveriam ser registradas de forma automatizada. Vários aparelhos e sistemas automatizados foram desenvolvidos nos últimos anos, como os Vibracorders, APEC, Medilog, Ethosys, mas o de uso mais freqüente é o IGER Behaviour Recorder. Esse aparelho registra os movimentos mandi-bulares totais e os distingue em bocados e movimentos mandibulares não associados ao pastejo, bem como o tempo efetivo de alimentação, que são posteriormente analisados pelo software Graze. O uso concomitante deste sistema automatizado e da técnica de dupla pesagem foi experimentado por Gonçalves (2007), cujo protocolo objetivou investigar o efeito da estrutura do pasto nativo na velocidade de ingestão de bovinos e ovinos (Figura 2).

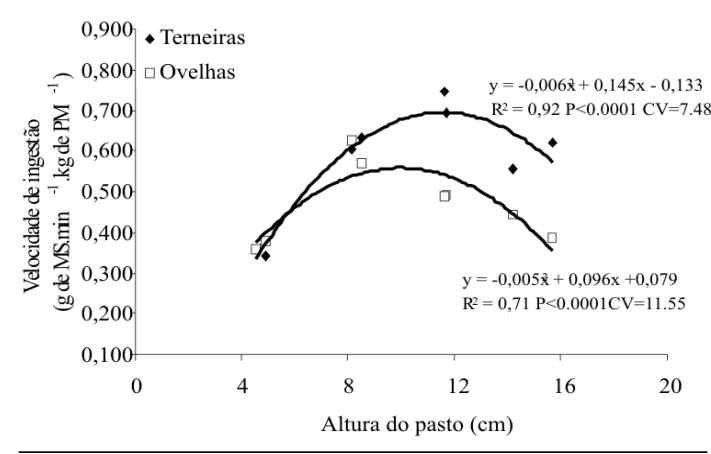

Figura 2 - Velocidade de ingestão de ovelhas e terneiras em pastagem nativa mantida com diferentes alturas (Gonçalves, 2007).
A informação gerada permitiu concluir que quando o pasto é manejado com alturas inferiores a 9,9 $\mathrm{cm}$ para ovinos e $11,4 \mathrm{~cm}$ para bovinos, a ingestão é limitada pela profundidade do bocado, que aumenta de forma linear com o aumento da altura do pasto $(b=0,58)$. Acima deste ponto, o consumo não se sustenta, pois a profundidade do bocado não é capaz de compensar a baixa densidade de forragem e a dispersão de lâminas nos estratos mais superiores do dossel, ocasionando queda na massa do bocado. Mais do que predizer o consumo dos animais por extensos períodos de tempo, esses resultados permitem definir e estabelecer metas de estrutura de pasto que otimizem a ingestão pelos animais em pastejo.

Apesar do uso de variáveis comportamentais ter alto potencial para estimar consumo, infelizmente tem havido uma banalização do seu uso por muitos pesquisadores que as usam de forma desvinculada de qualquer modelo preditivo e sem investigar adequadamente as relações de causa-efeito do processo de pastejo. Elas têm sido usadas somente como "variáveis emergentes" e tratadas como informações meramente adicionais nas publicações científicas, particularmente as nacionais.

\section{Avanços e considerações sobre a determinação dos componentes do consumo de longo prazo: excreção fecal e digestibilidade}

Uma das técnicas mais frequentemente utilizadas para estimar o consumo em pastejo é baseada no princípio de que a excreção fecal por um animal é inversamente proporcional à digestibilidade, mas diretamente relacionada à quantidade de alimento ingerido. Deste modo, o consumo pode ser estimado da seguinte forma:

\section{Consumo $($ g/dia $)=$ Produção fecal $(g /$ dia $) /$ (1-Digestibilidade)}

As metodologias desenvolvidas para estimar consumo com base nesta equação têm sido amplamente discutidas em congressos e publicações científicas, de modo que os potenciais e limitações de cada uma delas já foram detalhadamente descritos por inúmeros autores (e.g., Burns et al.; 1994; Minson \& Wilson, 1994; Peyraud et al., 1997; McMenniman, 1997; Aroeira

๑) 2007 Sociedade Brasileira de Zootecnia 
et al., 1997; Astigarraga et al., 1997; Moore \& Sollenberger, 1997; Dougherty, 1999; Lippke, 2002; Pedreira, 2002; Genro et al., 2004; Rodrigues et al., 2006; Berchielli et al., 2007).

Neste contexto, e procurando abordar aqueles menos discutidos anteriormente, propõe-se enfocar os principais aspectos dos protocolos de pesquisa que ainda geram insegurança, assim como sugerir alternativas práticas para melhorar a acurácia e a confiabilidade das estimativas de consumo em pastejo obtidas com base na produção fecal e digestibilidade da forragem.

\section{Metodologias para medir ou estimar a excreção fecal}

A excreção fecal por animais em pastejo pode ser medida diretamente, com uso de sacolas presas aos animais, que permitem a coleta total das fezes, ou estimada com uso de indicadores externos. A principal crítica ao uso das sacolas está relacionada ao possível desconforto do animal causado pelos arreios e/ou pelo peso das fezes, a ponto de modificar o comportamento ingestivo e o consumo de pasto. Adicionalmente, há também a possibilidade de haver perda dos excrementos para fora da sacola. Aparentemente, estes problemas parecem ser mais limitantes em bovinos do que em ovinos, principalmente com animais de alto nível de consumo e mantidos em pastagens com alto teor de umidade (Mélix et al., 1987; McMenniman, 1997; Moore \& Sollenberger, 1997; Lippke, 2002). Hatfield et al. (1993), num raro exemplo de comparação de métodos incluindo a coleta total de fezes com sacolas, não observaram diferenças no consumo, ganho de peso, produção fecal ou grau de estresse em ovinos utilizando sacolas ou recebendo indicadores. O grau de estresse dos animais, nesse estudo, aumentou em função do manejo, mas não pela presença da sacola em si.

A excreção fecal tem sido mais frequentemente estimada com o uso de indicadores externos. Independentemente do tipo, o uso de indicador externo permite estimar o consumo individual diário dos animais, mas não permite estimar o consumo de períodos diferentes de 24 horas, como durante uma refeição. Além disso, a concentração fecal de qualquer indicador externo varia amplamente ao longo do tempo, após o fornecimento, de modo que vários dias são necessários para excreção total da dosagem inicial fornecida. Em caso de dosagens diárias constantes, este tempo representa o número mínimo de dias para estabilizar a excreção fecal do indicador. Isto implica, também, que as condições experimentais devam ser semelhantes ao longo de todo o período de fornecimento do indicador e das amostragens. Em experimentos com pastejo rotativo, o erro nas estimativas de excreção fecal com indicador externo pode ser significativo se o período de ocupação, durante a fase de estabilização do indicador, for acima de 24 horas e diferente do período de coleta.

$\mathrm{O}$ óxido de cromo $\left(\mathrm{Cr}_{2} \mathrm{O}_{3}\right)$, apesar de suas conhecidas deficiências como marcador de fluxo de digesta, tem se consolidado como um dos indicadores mais utilizados para estimar o consumo de ruminantes em pastejo, particularmente por pesquisadores no Brasil, como Lopes et al. (2005), Cândido et al. (2005), Palieraqui et al. (2006), Gontijo Neto et al. (2006), entre vários outros. Entre as vantagens da sua utilização, podese citar o baixo custo e a relativa simplicidade dos procedimentos analíticos (Morenz et al., 2006). Contudo, algumas limitações associadas ao uso deste indicador, tais como a recuperação fecal incompleta (Mir et al., 1989; Soares et al., 2004) e sua irregularidade na excreção ao longo dia (Morenz et al., 2006; Kozloski et al., 2006), ainda persistem como problemas. Estes são ainda agravados se o cromo é fornecido em pó, seja por via oral ou cânula (Comeron, 1991). Apesar disso, o fornecimento do cromo em pó, embalado em cápsulas de papel ou gelatina, por via oral e com uso de sondas, ainda é a forma mais utilizada deste indicador. Este procedimento geralmente causa um estresse adicional aos animais e, além disso, as cápsulas podem ser regurgitadas, o que aumenta a variabilidade dos resultados. $\mathrm{O}$ fornecimento via ruminal e/ou em horários prévios aos horários de pastejo dos animais reduz o estresse, mas não evita os problemas associados à diferença de densidade do cromo em relação à digesta.

Penning (2004) compilou dados de literatura e concluiu que o período recomendado de dosagem dos marcadores, em geral, e do óxido de cromo em particular, é de 12 dias, compreendendo um período preliminar de 7 dias e coletas de fezes nos últimos 5 dias, num regime de dosagem de duas vezes ao dia em intervalos de aproximadamente 8

๑ 2007 Sociedade Brasileira de Zootecnia 
e 16 horas, com concomitante amostragem das fezes. As dosagens diárias recomendadas seriam, dependendo do tamanho do animal, entre 0,5 e 1 $\mathrm{g}$ para ovinos, e $5 \mathrm{a} 10 \mathrm{~g}$ para bovinos.

O estresse dos animais também pode ser reduzido com o fornecimento do indicador somente uma vez ao dia. Neste caso, os erros associados à flutuação diária da excreção do $\mathrm{Cr}_{2} \mathrm{O}_{3}$ podem ser minimizados pela obtenção de várias amostras de fezes ao longo de um dia, ou durante vários dias, mas com coletas em horários alternados, de forma a obter-se uma amostra composta contendo sub-amostras a cada 3 ou 4 horas de um ciclo de 24 horas (Kozloski et al., 2006). Outro procedimento proposto há mais de 20 anos é a coleta, no campo, de amostras de todas as fezes produzidas pelos animais (Mélix \& Peyraud, 1987). Nesse caso, para que seja possível a estimativa do consumo individual, pode-se fazer a identificação das fezes com partículas coloridas. Esse procedimento pode ser mais facilmente adotado quando existem animais fistulados no rúmen, onde partículas plásticas coloridas, de diferentes cores para cada animal, possam ser inseridas via cânula ruminal.

Outra alternativa metodológica é a mistura do indicador em um alimento concentrado peletizado (Wanyoike \& Holmes, 1981). Esta opção permite melhorar a associação do cromo com partículas da digesta, facilita o manejo, diminui o estresse causado aos animais e melhora o controle da quantidade ingerida do indicador. Contudo, a sua utilização em animais que não são dotados de cânula ruminal exige que o concentrado seja suficientemente palatável, característica que o óxido de cromo não possui. Deste modo, a sua adição a um alimento concentrado só pode ser realizada em pequenas quantidades, o que requer um método analítico sensível e preciso para determinar sua concentração fecal. Este procedimento foi avaliada por Ribeiro Filho et $a l$. (não publicado), concluindo-se que ela pode ser utilizada no caso do cromo ser analisado por espectro-fotometria de absorção atômica e se estiver presente nas fezes em concentrações superiores a $0,3 \mathrm{~g} / \mathrm{kg}$ de MO (Figura 3). A introdução do óxido de cromo em rações peletizadas se mostrou eficaz, também, na redução da flutuação diária da excreção do indicador (Zimmermann et al., 2005).

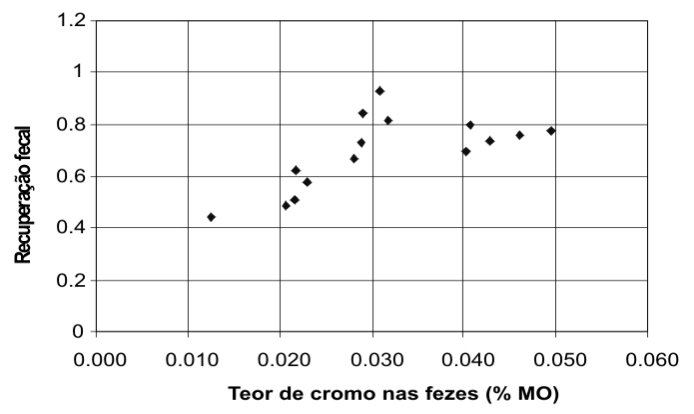

Figura 3 - Recuperação fecal do $\mathrm{Cr}_{2} \mathrm{O}_{3}$ quando fornecido misturado em uma ração peletizada na proporção de $0,5 \%$ da matéria natural para novilhos recebendo azevém verde. Medido por espectrofotometria de absorção atômica (Ribeiro Filho et al., não publicado)

Como alternativa ao uso de óxido de cromo, vários outros indicadores também têm sido utilizados. O Iterbium associa-se mais fortemente às partículas da digesta e é mais palatável que o óxido de cromo. No entanto, é importado e oneroso. Recentemente, foi lançado no mercado brasileiro o LIPE ${ }^{\circledR}$, um polímero hidroxifenilpropano modificado (ou uma lignina purificada de Eucalipto). Além de ser produzido nacionalmente, o período de adaptação para que sua excreção alcance o equilíbrio parece ser menor que o do óxido de cromo (Rodriguez et al., 2006; Berchielli et al., 2007). Os estudos validando sua utilização, contudo, são ainda incipientes. Além disso, a determinação deste indicador é feita por espectrometria no infravermelho, que é um equipamento relativamente oneroso e ausente na maioria dos laboratórios de pesquisa. Além disso, a espectrometria no infravermelho requer adequada calibração com um grande número de amostras relativamente homogêneas em sua constituição química (Fontaneli \& Fontaneli, 2007).

\section{Metodologias para estimar a digestibilidade}

A digestibilidade da forragem consumida em situação de pastejo não pode ser medida diretamente. Independente da espécie forrageira, se tropical ou temperada, a digestibilidade do material selecionado pelos animais na maioria das situações de pastejo tem qualidade e digestibi-lidade relativamente alta, acima de $60 \%$. Isto implica que erros associados às estimativas de consumo em pastejo são mais afetados por erros das estimativas de digestibilidade do que de produção fecal (Figura 4).

\section{2007 Sociedade Brasileira de Zootecnia}




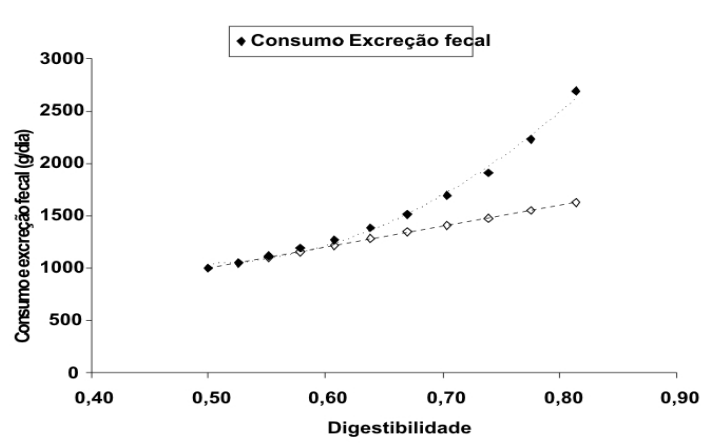

Figura 4 - Efeito teórico da digestibilidade sobre o consumo e a excreção fecal.

A digestibilidade da forragem consumida por animais em pastejo pode ser estimada com base na análise de amostras da forragem, das fezes ou de ambos.

\section{Estimativa da digestibilidade a partir de amostras da forragem}

A digestibilidade de amostras de forragem pode ser estimada através de ensaios de digestibilidade in vivo, in situ, in vitro, ou com base na sua composição químico-bromatológica. A crítica comum a qualquer dos métodos é que um único valor de digestibilidade é usado para todos os animais (Dove \& Mayes, 1991) e a acurácia das estimativas depende da representatividade da amostra analisada em relação à forragem consumida.

Para minimizar os erros de amostragem, existe a recomendação de coletar amostras de forragem por simulação de pastejo ou com uso de fístulas esofágicas. A implantação, mas principalmente a manutenção de fístulas no esôfago, são aspectos limitantes desta técnica e sua utilização tem sido rara, pois como comentado anteriormente, as principais críticas ao uso de fístulas estão relacionadas à mudança no comportamento ingestivo dos animais e às restrições éticas e legais ao seu uso. Adicionalmente, também pode haver contaminação da amostra ingerida com saliva. A simulação de pastejo, por outro lado, tem sido a técnica amostral mais comumente utilizada nestes experimentos. A sua limitação reside no fato de que a decisão sobre a amostragem é subjetiva ao observador. Além disso, o grau de variação entre amostradores, assim como o número mínimo de amostradores e de amostragens por unidade experimental ou por período, entre outros, são aspectos críticos. O grau de heterogeneidade do pasto também interfere na amostragem, e este é considerável mesmo em pastagens monoespecíficas (Carvalho et al., 2001).

A digestibilidade da forragem tem sido comumente estimada in vitro, por incubação microbiológica ou enzimática. No entanto, além de terem baixa reprodutibilidade entre laboratórios, nenhum esses métodos reproduz adequadamente o processo de digestão in vivo. Esta deficiência pode ser contornada pela validação da técnica in vitro, em cada laboratório, com base em ensaios de digestibilidade in vivo, gerando-se equações locais de ajuste de dados. Todavia, este procedimento raramente tem sido adotado.

A técnica original de Tilley \& Terry foi modificada de maneira que a amostra é incubada em saquinhos de poliamida ou poliéster, e o resíduo da incubação é tratado com solução detergente neutro. Com esta variação, o método estima a digestibilidade verdadeira da matéria orgânica (MO) e, para calcular a digestibilidade aparente, é necessário que se faça uma correção para a excreção fecal de MO endógena. Weiss et al. (1992) usam um valor fixo de desconto de 7\%, mas ensaios de digestibilidade in vivo com ovinos indicam valores superiores, em torno de $14 \%$ (Kozloski, com. pes., 2007). De qualquer forma, a técnica in vitro permite caracterizar e diferenciar alimentos ou dietas que tenham diferenças relativamente grandes de digestibilidade (Figura 5), mas raramente tem exatidão suficiente para diferenciar a qualidade de forragens ao longo do seu estágio vegetativo (Figura 6).

Assim, como destacado por Allen \& Linton (2007), as técnicas laboratoriais de avaliação da digestibilidade dos alimentos são de grande valia para diferenciar alimentos, mas pouco sensíveis para predizer os processos in vivo.

A estimativa da digestibilidade da forragem ingerida torna-se mais complexa ainda se os animais a pasto são suplementados. Para detalhes metodológicos e discussão sobre a estimativa de consumo nestas condições o leitor é referido a Moore \& Sollenberger (1997).

\section{Estimativa da digestibilidade a partir de amostras das fezes}

A digestibilidade da forragem consumida também pode ser estimada com alto grau de

๑ 2007 Sociedade Brasileira de Zootecnia 


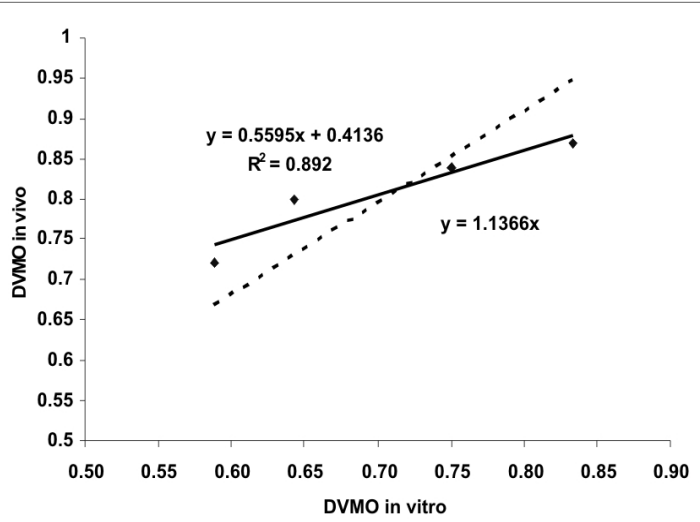

a)

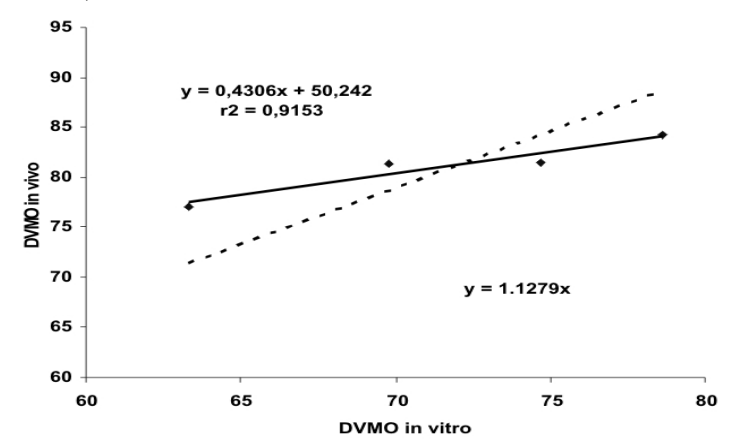

b)

Figura 5 - Relação entre a digestibilidade verdadeira da matéria orgânica (DVMO) de dietas com diferentes proporções silagem e concentrado estimada in vitro ou em ensaio in vivo com ovinos (a) ou bovinos (b) (Kozloski et al., não publicado).

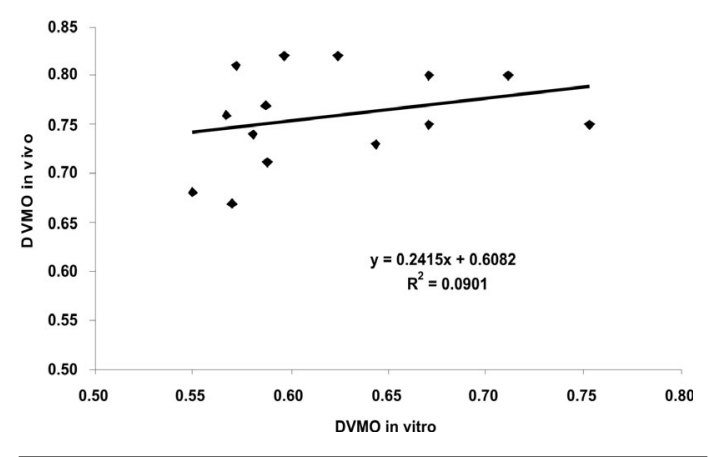

Figura 6 - Relação entre a digestibilidade verdadeira da matéria orgânica (DVMO) de feno de gramíneas tropicais com diferentes idades de rebrota estimada in vitro ou em ensaios in vivo com ovinos. (Kozloski et al., não publicado).

precisão com base na concentração fecal de indicadores, como o nitrogênio (Lancaster, 1949; Bartiaux-Thill \& Oger, 1986; Comeron \& Peyraud, 1993, Boval et al., 1996, 2003; Lukas et al., 2005). Esta técnica assume que o teor de $\mathrm{N}$ nas fezes varia inversamente à quantidade de matéria seca fecal excretada (Demarquilly et al.,
1995). As principais críticas a este método são que, geralmente, há elevada variabilidade individual nos resultados, além de haver a necessidade de se obter uma equação para cada situação de pastejo (espécie forrageira, nível de adubação nitrogenada, ciclo vegetativo, localização geográfica, entre outros). Isto ocorre porque a excreção fecal de $\mathrm{N}$ de origem endógena e, em menor proporção, o residual do alimento, são dependentes do consumo de $\mathrm{N}$ e, diferente do assumido pelo método, pode variar proporcionalmente ao consumo de matéria orgânica indigestível (Van Soest, 1994; NRC, 1996). Embora com alta variabilidade individual, essa resposta também foi observada em experimentos de digestibilidade com ovinos (Figura 7).

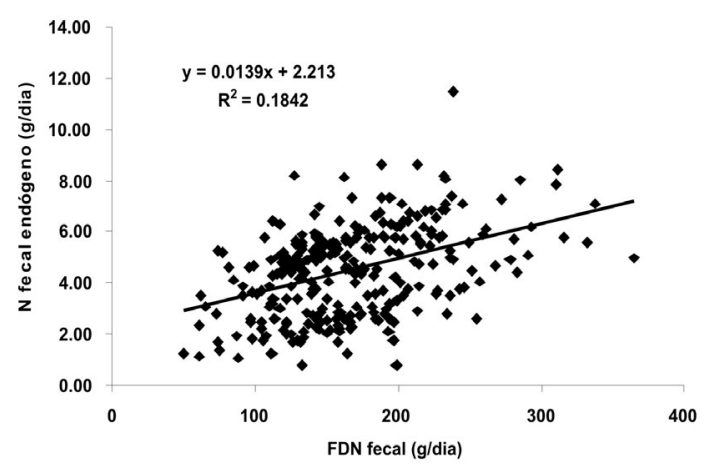

Figura 7 - Relação entre excreção fecal de FDN e de $\mathrm{N}$ endógeno em ovinos alimentados com dietas variadas. (Kozloski et al., não publicado).

A inclusão de covariáveis relacionadas à pastagem (teor em $\mathrm{N}$ ou FDA) nas equações diminui os erros de predição da digestibilidade da forragem a partir de indicadores fecais (Ribeiro Filho et al., 2003, 2005). No entanto, se a excreção total de $\mathrm{N}$ é diretamente proporcional à excreção de resíduo indigestível, ela poderia ser utilizada para predizer consumo de pasto. Para testar essa hipótese, dados de dez ensaios de digestibilidade com ovinos, conduzidos no Laboratório de Nutrição de Ruminantes da UFSM, foram compilados e analisados. Foi observado que a excreção de $\mathrm{N}$ de origem endógena, estimada como a concentração total de $\mathrm{N}$ menos o $\mathrm{N}$ presente na fibra em detergente neutro, representou $77 \pm 7 \%$ do $\mathrm{N}$ fecal total, e que a excreção de ambos, $\mathrm{N}$ total e N endógeno, foi variável como proporção do peso vivo dos animais (médias \pm desvio padrão de $193 \pm 61$ e $150 \pm 51 \mathrm{mg} / \mathrm{kg}$ de peso vivo, respectivamente). Em função disto, foi observado uma 
baixa relação entre concentração fecal de $\mathrm{N}$ e digestibilidade da MO (Figura 8).

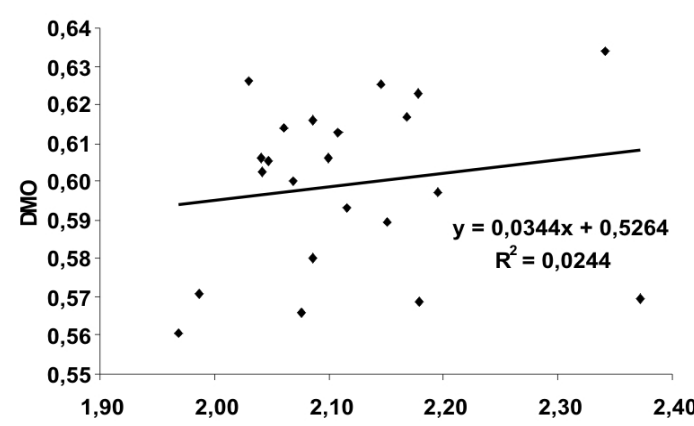

a)

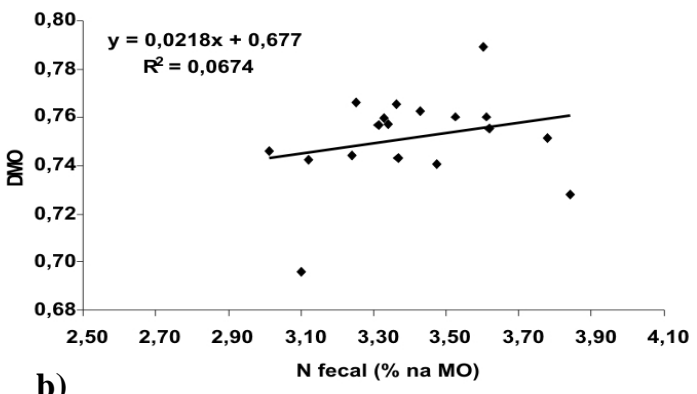

b)

Figura 8 - Relação entre concentração fecal de $\mathrm{N}$ e digestibilidade aparente da matéria orgânica (DMO) em ovinos alimentados com feno de capim elefante anão (a) ou silagem de sorgo mais concentrado (b) a diferentes níveis de consumo. ( Kozloski et al., não publicado).

No entanto, foi verificado uma alta correlação entre excreção total de $\mathrm{N}$ e consumo de $\mathrm{MO}$ (Figura 9).

Estes resultados indicam que a técnica tem um alto potencial para estimar consumo por animais em pastejo. Ela implicaria, no entanto, em medidas acuradas da produção fecal dos animais a pasto e na condução de ensaios de digestibilidade em paralelo, com animais alimentados em diferentes níveis de consumo com o pasto cortado verde.

\section{Estimativa da digestibilidade a partir de amostras das fezes e da forragem}

A digestibilidade da forragem pode ser também estimada com base na denominada técnica da relação, com uso de marcadores internos que são componentes naturais e indigestíveis da forragem. O uso de marcadores internos, em teoria, expressa o real processo de digestão dos animais em pastejo. Os mais utilizados são os alcanos e resíduos de incubação in vitro ou in situ, por um período mínimo de 144 horas, que incluem matéria seca (MSi), fibra detergente ácido (FDAi) ou fibra em

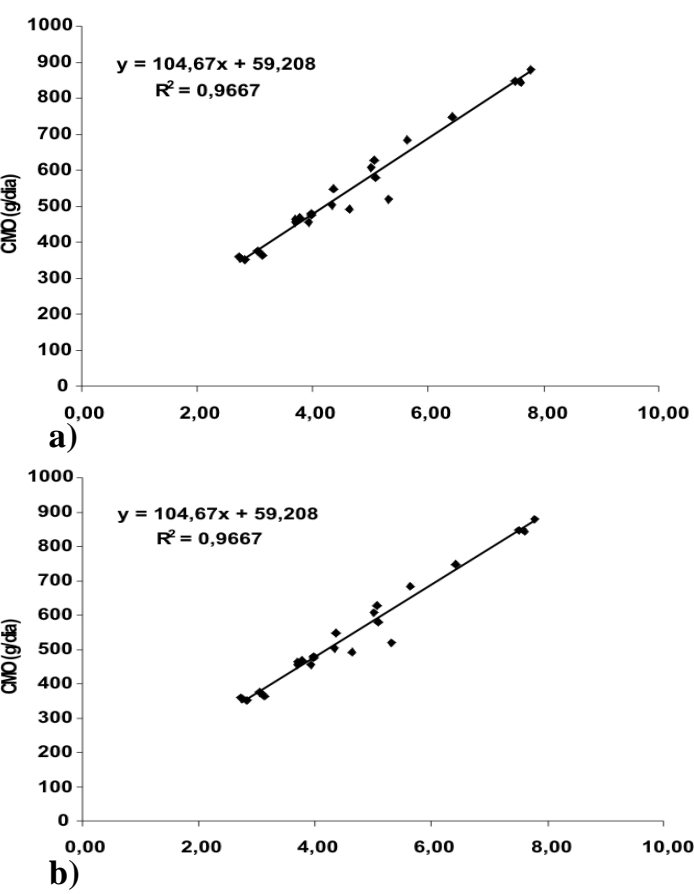

Figura 9 - Relação entre excreção fecal de $\mathrm{N} \mathrm{e}$ consumo de matéria orgânica (CMO) em ovinos alimentados com feno de capim elefante anão (a) ou silagem de sorgo mais concentrado (b) a diferentes níveis de consumo (Kozloski et al., não publicado).

detergente neutro (FDNi) indigestíveis. O uso de alcanos como indicador interno será considerado separadamente nesta revisão. Cinza insolúvel em ácido ou em detergente ácido, assim como a lignina, também têm sido utilizados. A crítica ao uso das cinzas insolúveis está associada à sua baixa concentração nas amostras, que diminui a precisão das estimativas, ou à possibilidade de contaminação das amostras com solo, superestimando suas concentrações. A lignina, por sua vez, é inadequada como marcador interno de digestibilidade porque ela é parcialmente digerida no rúmen. A MSi, FDAi e FDNi, por sua vez, têm sido mais frequentemente testados e utilizados. O grau de recuperação e, deste modo, a precisão e exatidão das estimativas de digestibilidade e consumo utilizando estes indicadores tem sido variável (Berchielli et al., 2005; Rodrigues et al., 2006). Isto ocorre porque estas frações não constituem unidades químicas uniformes e constantes em todos os alimentos, e tampouco há um método padrão definido para sua determinação (Lippke, 2002). No entanto, estes problemas não inviabilizam o uso destes indicadores, desde que em cada experimento individual, independentemente da técnica de determinação utilizado, o

๑ 2007 Sociedade Brasileira de Zootecnia 
seu grau de recuperação seja medido. Isto implica no uso de sacolas de coleta total de fezes em alguns dos animais experimentais ou na condução de ensaios paralelos de digestibilidade in vivo, em que o pasto é cortado e fornecido verde para animais mantidos em gaiolas ou baias. Este procedimento também deveria ser adotado para medir o grau de recuperação de indicadores externos de produção fecal.

Dados de consumo estimados com base em diferentes métodos geralmente têm baixa correlação (Figura 10).

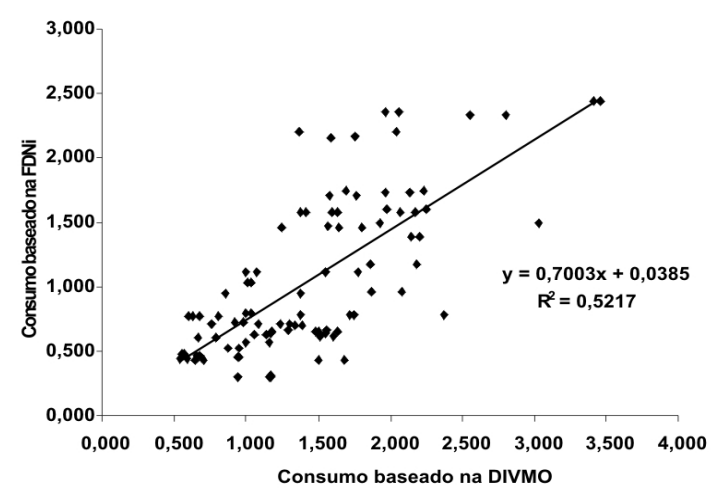

Figura 10 - Estimativas de consumo de ovinos (kg de matéria seca/dia) em pastagem de milheto calculadas com base em valores de digestibilidade da forragem estimadas in vitro ou com o marcador interno fibra detergente neutro indigestível (FDNi). A digestibilidade in vitro foi determinada ao incubar as amostras de forragem durante 48 horas com fluído ruminal tamponado, tratando o resíduo da incubação com detergente neutro. Os valores representaram a digestibilidade verdadeira da matéria orgânica (DIVMO). A digestibilidade aparente foi calculada reduzindo-se $14 \%$ dos valores de DIVMO. A FDNi foi determinada pela incubação in situ em bovinos fistulados de amostras da forragem e das fezes durante 144 horas (Kozloski et al., não publicado).

Deste modo, sempre que as estimativas de digestibilidade não sejam adequadamente validadas com base em resultados de coleta total de fezes e/ou em ensaios de digestibilidade in vivo, as estimativas de consumo são mais de caráter indicativo ou especulativo do que reais, e raramente permitem detectar efeitos dos tratamentos impostos nos estudos com animais em pastejo.

\section{Estimativas de consumo e seleção de dieta usando alcanos}

O uso de alcanos como marcador da excreção

๑ 2007 Sociedade Brasileira de Zootecnia fecal (externo) ou da digestibilidade (interno) foi inicialmente proposto por Mayes \& Lamb (1984). Os alcanos das plantas são encontrados na cera cuticular (Chibnall et al., 1934) e são constituídos, predominantemente, por cadeias de carbonos ímpares, de 25 a 35 carbonos. O interesse pela composição química da cera cuticular das plantas aumentou quando as técnicas analíticas, principalmente a cromatografia gasosa e a líquida, se tornaram mais acuradas. Oró et al. (1965) já haviam observado semelhança entre o padrão de alcanos das fezes e da forragem consumida por bovinos. Posteriormente, Grace \& Body (1981) mostraram que a cera cuticular das plantas continha hidro-carbonos variados, sem cadeias ramificadas. As características principais destes compostos eram: i) o comprimento da cadeia de carbonos dos principais alcanos estaria entre o $\mathrm{C}_{25}$ (pentacosano) e o $\mathrm{C}_{35}$ (pentatriacontano); ii) os alcanos de cadeia ímpar estariam presentes em maiores quantidades que os de cadeias pares; iii) $\mathrm{C}_{29}$ (nonacosano), $\mathrm{C}_{31}$ (entriacontano) e $\mathrm{C}_{33}$ (tritriacontano) seriam os alcanos mais abundantes, entretanto, existiria uma marcada diferença em seus níveis e padrões, conforme a espécie e parte da planta (Dove \& Mayes, 1991).

Uma das vantagens dos alcanos, em relação aos outros marcadores (e.g., óxido de cromo, elementos de terras raras, etc.), é que em uma única análise se determina o indicador externo e o interno (Mayes et al., 1986a). Apesar de importado, o uso de alcanos por pesquisadores brasileiros vem se intensificando (e.g., Oliveira et al., 1997; Genro, 1999, Sarmento, 2003; Oliveira 2003).

Dove \& Mayes (1996) compilaram resultados de vários estudos em que foi testada a validação do uso de alcanos como marcador da excreção fecal. Esses resultados são apresentados na Tabela 2 e demonstram o alto grau de exatidão deste marcador, mais alto que o obtido com outros indicadores externos como, por exemplo, o óxido de cromo (Le Du \& Penning, 1982).

A vantagem do uso dos alcanos como marcador, em relação ao óxido de cromo, também foi constatada por Genro et al. (2004). Os autores compararam os valores de consumo de matéria seca estimados com uso dos alcanos ou de óxido de cromo, com aqueles preditos pelo Sistema de Carboidratos e Proteína Líquidos de Cornell (CNCPS; Fox et al., 2004). Os resultados são apresentados na Figura 11. 


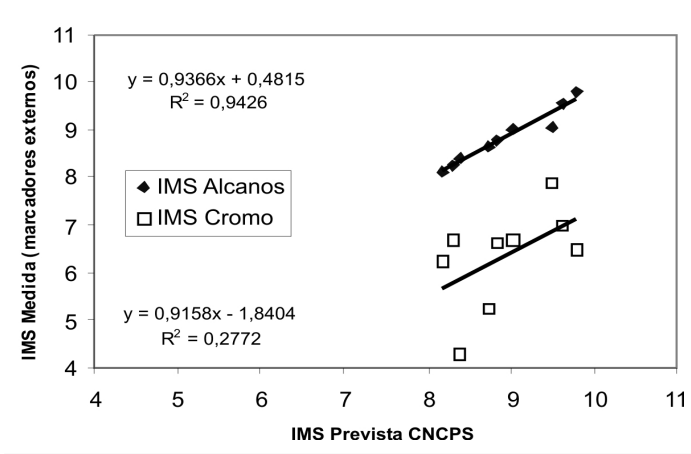

Figura 11 - Regressão entre os valores de consumo preditos pelo CNCPS e os consumos medidos por marcadores externos óxido de cromo e alcanos em pastagens tropicais no Brasil-Central (Genro et al., 2004)

Os valores absolutos, assim como o grau de exatidão e precisão das estimativas de consumo obtidas com alcanos, foram superiores aos obtidos com óxido de cromo. A validação absoluta do método do duplo alcano com animais em pastejo, contudo, não pode ser feita por não haver um padrão adequado para comparação. Adicionalmente, fatores que poderiam afetar a acurácia da técnica, tais como variações no padrão de pastejo, dentro e entre dias, não foram ainda suficientemente elucidados.

Além de estimar digestibilidade e produção fecal com grande acurácia, é possível usar a mesma análise do perfil de alcanos para avaliar a composição da dieta, o que se constitui numa grande vantagem desse método para estudar as interações planta-animal (Dove \& Mayes, 1991). O princípio do método é que o padrão de alcanos na extrusa esofágica, digesta ou fezes, provenientes de uma pastagem botanicamente complexa, será o resultado de uma combinação dos perfis de alcanos presentes nas espécies forrageiras que contribuíram para aquela mistura (Dove \& Mayes, 2003).

O uso desta técnica tem sido experimentado no Brasil (Cortês et al., 2005; Genro et al., 2005). Quando a dieta é composta por poucas espécies, os resultados estimados são muito próximos da composição conhecida (Dove \& Mayes, 1996; Hameleers \& Mayes, 1998; Dove \& Mayes, 2003; Cortês et al., 2005). Porém, ele consegue estimar, com precisão, somente até quatro componentes de uma pastagem com flora mais complexa, como as pastagens naturais (Dove, 1992). Nestas situações, a exatidão das estimativas pode ser aumentada pelo uso combinado dos alcanos com outros potenciais marcadores também encontrados na cera das plantas, como os alcenos, alcanos de cadeia ramificada, álcoois de cadeia longa, esteróis e ácidos graxos de cadeia longa (Mayes \& Dove, 2000; Dove \& Mayes, 2003; Bugalho et al., 2004; Ali et al., 2005; Fraser et al., 2006; Oliván et al., 2007). Esses compostos apresentam diferentes concentrações em diferentes espécies e partes das plantas, e podem ser medidos na mesma marcha analítica dos alcanos.

\section{Uso de alcanos para estimar consumo de animais recebendo suplementação}

Como visto anteriormente, vários fatores podem afetar a acurácia das estimativas de consumo em pastejo. Contudo, isto se torna ainda mais complexo se os animais a pasto são suplementados. Detalhes metodológicos e discussão sobre a estimativa de consumo nestas condições já foram feitas previamente por Moore \& Sollenberger (1997). Deste modo, serão

Tabela 2 - Comparação de consumos conhecidos de ovinos e bovinos com consumos de forragem estimados usando alcanos.

\begin{tabular}{lcc}
\hline Tipo de animal e condições experimentais & Consumo conhecido de MS & Discrepância\% \\
\hline Cordeiros (36 kg); forragem fresca & $579 \mathrm{~g} / \mathrm{dia}$ & 0 \\
Cordeiros (10 semanas de idade); leite + forragem fresca & $112-273 \mathrm{~g} / \mathrm{dia}$ & 0,20 \\
Ovinos; azevém perene & $913,5 \mathrm{~g} / \mathrm{dia}$ & $-0,02$ \\
Cordeiros (34 kg); forragem fresca & $778 \mathrm{~g} / \mathrm{dia}$ & 2,57 \\
Ovinos; trevo persa seco & $699-1154 \mathrm{~g} / \mathrm{dia}$ & $-0,50$ \\
Vacas de corte secas & $4 \mathrm{~kg} / \mathrm{dia}$ & $-1,70$ \\
Vacas de leite no fím da lactação; forragem fresca & $14,18 \mathrm{~kg} / \mathrm{dia}$ & $-0,06$ \\
Vacas de leite no início da lactação: & & \\
Silagem & $4,76 \mathrm{~kg} / \mathrm{dia}$ & 2,10 \\
Pastagem & $12,05 \mathrm{~kg} / \mathrm{dia}$ & $-2,60$ \\
Vacas de leite & $9,47 \mathrm{~kg} / \mathrm{dia}$ & $-1,90$ \\
\hline
\end{tabular}

Adaptado de Dove \& Mayes (1996). 
abordados, nesta revisão, somente alguns aspectos adicionais e/ou específicos do uso de alcanos para estimar consumo nestas condições.

Para superar dificuldades metodológicas, alguns pesquisadores têm fornecido o suplemento aos animais de forma individual (Garcia, 2004 e Santana, 2006). Embora isto seja vantajoso do ponto de vista experimental, esta prática não permite identificar a expressão natural das variações existentes entre animais quando suplementados em grupo, que é o manejo comumente usado nos sistemas de produção no Brasil.

De acordo com Dove \& Mayes (1996), é possível se estimar o consumo individual do suplemento com uso dos alcanos quando a composição de alcanos do suplemento é suficientemente diferente da composição do pasto, e a taxa de recuperação do alcano é conhecida. Se a concentração de alcanos dos componentes da dieta for similar ou em concentrações muito desiguais, a estimativa do consumo pelos animais tem baixa precisão (Garcia et al., 2000). Hameless \& Mayes (1998), contudo, verificaram que esta técnica foi eficiente para estimar o consumo individual de vacas de leite pastejando cevada suplementada com silagem de gramínea.

A precisão das estimativas de consumo de pasto e suplemento podem ser incrementadas também pelo uso combinado de alcanos com outros marcadores, como o isótopo de carbono ${ }^{13} \mathrm{C}$ (Garcia et al., 2000; Machado et al., 2006), analisados nas fezes.

Este método baseia-se em que as concentrações do isótopo estável de ${ }^{13} \mathrm{C}$ sejam diferentes entre as forrageiras tropicais e temperadas e tem a vantagem de que a absorção de ${ }^{13} \mathrm{C}$ pela planta permanece estável em uma faixa razoável de condições ambientais (Smith 1972). Além disso, as concentrações de ${ }^{13} \mathrm{C}$ da raiz até a semente são similares. Este marcador tem sido usado para diferenciar a ingestão de plantas $\mathrm{C}_{3} \mathrm{e}_{4}$ pelos animais (Jones et al., 1979). O uso combinado de alcanos e ${ }^{13} \mathrm{C}$ foi eficiente também para diferenciar a ingestão de pastagens temperadas e silagem de milho (Garcia et al., 2000) e de pastagens temperadas e suplementos a base de milho e farelo de soja (Machado et al., 2006). Alguns resultados da composição de alcanos e ${ }^{13} \mathrm{C}$ de algumas forrageiras temperadas e suplementos são apresentados na Tabela 3. O uso de

๑ 2007 Sociedade Brasileira de Zootecnia
${ }^{13} \mathrm{C}$, no entanto, não permite diferenciar espécies dentro dos grupos $\mathrm{C}_{3}$ e $\mathrm{C}_{4}$, e sua determinação depende de equipamento pouco comum na maioria dos laboratórios de pesquisa.

\section{Outras técnicas ou procedimentos emergentes}

O uso de perfilhos marcados e da técnica de mensuração de fluxo de tecidos no perfilho tem sido recentemente apresentada como uma alternativa, não somente para estimar consumo, mas também para avaliar outros processos, como crescimento e senescência, que ocorrem na parte aérea de comunidades vegetais submetidas ao pastejo (Pontes et al., 2004). O princípio do método é que os processos que ocorrem em cada perfilho seja representativo do que ocorre no pasto como um todo, desde que seja determinado a densidade populacional de perfilhos. Nesta técnica, uma amostra da população de perfilhos é marcada, usualmente com fios de telefone, e os perfilhos são classificados e medidos em unidades métricas, sempre observados em intervalos usualmente não superiores a 3 dias, por ciclos não superiores a 40-45 dias. Ao longo do ciclo de avaliação, amostras de perfilhos são obtidas para a determinação da densidade de perfilhos/unidade de área, bem como para a transformação da unidade métrica dos componentes morfológicos dos perfilhos em unidade de massa (Cauduro et al., 2007). As limitações desta técnica residem nos inúmeros procedimentos sujeitos a erro experimental, bem como a população de perfilhos marcados e amostrados no campo represente efetivamente a população de perfilhos encontrada no pasto. Outra limitação é que todas as informações descrevem unidades de processos por unidade de área, o que significa que o consumo individual dos animais seja estimado como a quantidade forragem que foi pastejada dividida pelo número de animais presentes na pastagem. Esta técnica, de forma geral, superestima o consumo. No entanto, tem baixo custo e permite obter informações sobre o fluxo dos tecidos no pasto e sobre a natureza da dieta selecionada pelo animal (e.g., Pontes et al., 2004), bem como calcular índices de preferência relacionados aos diferentes componentes morfológicos oferecidos ao animal. Por exemplo, Palhano et al. (2005) calcularam índices de seletividade ativa e passiva de novilhas pastejando 
Tabela 3 - Concentrações dos principais alcanos (mg / $100 \mathrm{~g}$ de $\mathrm{MS})$ e concentração de ${ }^{13} \mathrm{C}\left(\delta^{13} \mathrm{C}\right.$ abundancia por 1000 de ${ }^{13} \mathrm{C}$ relativo ao carbonato padrão).

\begin{tabular}{lccccc}
\hline & $\mathbf{C}_{\mathbf{2 9}}$ & $\mathbf{C}_{\mathbf{3 1}}$ & $\mathbf{C}_{\mathbf{3 3}}$ & $\mathbf{\delta}^{\mathbf{1 3}} \mathbf{C}$ & Referência \\
\hline Experimento 1 & 14,9 & 29,3 & 7,95 & $-28,7$ & Garcia et al., 2000 \\
Forrageira** & 1,0 & 1,4 & 1,0 & $-11,7$ & \\
Silagem de milho & & & & & \\
Experimento 2 & 6,9 & 13,4 & 12,6 & $-29,9$ & \\
Forrageira** & 1,1 & 0,8 & 1,0 & $-11,5$ & \\
Silagem de milho & & & & & Machado et al., 2006 \\
Experimento 1 & 156,2 & 333,1 & 75,2 & -27.9 & \\
Forrageira* & 1,1 & 0,8 & 0,6 & -11.1 & \\
Grão de milho & & & & & \\
Experimento 2 & 251,5 & 499,2 & 11,8 & $-28,2$ & \\
Forrageira* & 1,1 & 0,8 & 0,6 & -11.1 & \\
Grão de milho & 3,1 & 2,7 & 2,2 & $-25,0$ & \\
Farelo de soja & & & & \\
\hline
\end{tabular}

*Pasto de Festuca arundinacea e Trifolium repens. ** Pasto de Lolium perenne e Trifolium repens.

capim-mombaça, e descreveram quantitativamente um processo considerado como qualitativo.

O grau de seleção de plantas e o consumo também podem ser estimados por observação direta e próxima do animal, mimetizando suas ações de pastejo. A despeito das óbvias limitações envolvidas neste tipo de técnica (Gordon, 1995), o procedimento recentemente trazido por Agreil \& Meuret (2004) surpreende pela precisão e natureza das variáveis-resposta que podem ser obtidas. Os autores produziram uma escala codificada de categorias de bocados, e sua ocorrência é observada em tempo real à atividade de pastejo. Os autores produziram uma escala codificada de categorias de bocados cuja ocorrência é observada em tempo real, concomitante à atividade de pastejo. Uma vantagem desse método é a possibilidade de caracterizar a dinâmica ingestiva em vegetações altamente complexas, onde outras técnicas têm limitações não somente de acurácia, mas até mesmo de aplicação (Agreil \& Meuret, 2004).Além disso, o método fornece informações sobre a dinâmica do comportamento ingestivo em diferentes escalas temporais: consumo de longo prazo, cinética ingestiva em nível de refeição e quantificação do processo de aquisição do bocado.

Outra metodologia recentemente proposta tem por base medidas bioacústicas (Laca \& Wallis De Vries, 2000). O princípio está em que os movimentos mandibulares têm características acústicas que permitem sua distinção, e a intensidade e tipo das ondas sonoras produzidas pelo pastejo estariam associadas com a quantidade de forragem ingerida. Isto significaria um enorme avanço em relação a outros métodos, pois permitiria a quantificação da massa do bocado (Laca \& Wallis De Vries, 2000). Ungar \& Rutter (2006) compararam esta técnica com o IGER Behaviour Recorder e concluíram por uma razoável correspondência entre procedimentos, no que diz respeito à classificação dos movimentos mandibulares. Ademais, as medidas acústicas são capazes de identificar os bocados compostos. Segundo Gibb (com. pes., 2007), há evidências de que esta técnica possa predizer também o tipo de espécie vegetal ingerida pelo animal, bem como a sua digestibilidade. Por essas razões, é considerada por ele como a novidade técnica que representa o maior avanço dentre as metodologias para estimar consumo emergentes na última década.

\section{Considerações sobre procedimentos estatísticos}

Uma questão central associada ao delineamento e à análise de dados obtidos em estudos com animais em pastejo é a definição da unidade experimental. Penning (1998) reporta a descoberta dos fenômenos de facilitação social e alelomimicria (sincronização de atividades), além da competição conjunta pelo recurso alimentar (o que um animal está pastando, o outro não pode), para embasar a impossibilidade de uso individualizado dos animais (ou grupos de animais dentro de um mesmo piquete) como repetições em experimentos de pastejo. Segundo Rook (1998), os delineamentos que usam animais ou animais dentro de

๑ 2007 Sociedade Brasileira de Zootecnia 
grupos como repetições assumem implicitamente que o procedimento em pastejo dos mesmos, e consequen-temente o consumo e a produção animal, sejam independentes dos demais animais no mesmo piquete. No entanto, há uma base de informações consolidada que atesta a dependência entre animais dentro do grupo, e a dependência das observações na mesma unidade amostral (animal/grupo) ao longo do tempo (Rook, 2004).

A título de levantamento, e de se traçar um perfil da produção científica nacional, analisouse 29 artigos publicados nas revistas científicas de maior renome em nossa literatura. Todos avaliavam consumo em pastejo e foram publicados nos últimos 10 anos. Destes, 17 utilizaram animais como unidades experimentais, 10 utilizaram o piquete, e em 2 não se conseguiu definir, com precisão, aquilo que constituía a unidade experimental. Além da predominância do uso de animais como repetição foi observado, também, o uso de "pseudo-repetições", onde a unidade experimental para medir atributos do pasto é diferente da usada para se medir atributos dos animais. A partir deste levantamento, tem-se a percepção de que estes problemas se verificam mais comumente em equipes que têm mais interesse, ou enfoque, na medição dos atri-butos dos animais do que do pasto, tratando indevidamente a complexidade do ambiente pastoril.

Experimentos de pastejo que não tenham pelo menos oito piquetes, qualquer que seja o arranjo experimental ou o método de pastejo, dificilmente atingem suficiência estatística e não são recomendáveis (Bransby, 1989). Portanto, e na medida em que não haja restrição científica ou debate algum que conteste aqueles que compreendem ser o piquete a unidade experimental de experimentos de pastejo, recomenda-se que as seguintes considerações sejam levadas em conta em estudos de determinação do consumo em situações de pastejo:

i) os piquetes devem se constituir nas unidades experimentais ainda que o interesse principal resida sobre parâmetros dos animais;

ii) o grupo de animais não deve ser pequeno (e.g., para ovinos, em grupos inferiores a 4-5 animais o tempo destinado a vigilância interfere no tempo de pastejo);

iii) animais que recebam diferentes tratamentos não relacionados à pastagem devem pastejar piquetes separados, com rotação dos animais nos mesmos para se obter condições similares entre tratamentos, se esta for uma exigência do protocolo experimental (vide Rook, 2004);

\section{Conclusões}

Este artigo poderá desapontar aqueles cuja única expectativa fosse obter, finalmente, uma recomendação definitiva de um método para estimar consumo por animais em pastejo. Esta recomendação ainda não existe, se é que um dia existirá. Não obstante, há avanços muito claros nesta área. As técnicas de estimação de consumo de curto prazo têm produzido um notável conhecimento do processo de captura da forragem pelo animal em pastejo. Elas interagem com técnicas de avaliação do comportamento ingestivo para estimação do consumo de longo prazo. No entanto, tem se constatado o seu uso de forma descontextualizada e indiscriminada. A simples extrapolação dos resultados para a escala de longo prazo não é, absolutamente, recomendada.

O uso da técnica dos alcanos para estimar consumo, digestibilidade e composição da dieta, com a associação ou não de outras substâncias como marcadores, vem se consolidando como uma metodologia consistente e de potencial para auxiliar no entendimento das relações existentes entre os herbívoros e seu ambiente pastoril. A utilização dos alcanos como marcador tem sido incrementada nos países desenvolvidos, porém, no Brasil, seu uso ainda é incipiente.

Devido à facilidade de aquisição e de análise, o óxido de cromo continua sendo o marcador mais utilizado nos estudos com animais em pastejo no Brasil (utilizado em 66\% dos trabalhos levantados para se traçar o perfil do uso de técnicas de estimação do consumo). Em função disto, este trabalho apresenta propostas de procedimentos que visam diminuir as deficiências inerentes ao seu uso, e consequentemente, melhorar as estimativas de consumo utilizando este indicador. Entre elas, destaca-se a importância de se medir o grau de recuperação do indicador nas fezes; fornecer o indicador misturado a pequenas quantidades de concentrado; coletar amostras de fezes em diferentes horários do dia ou diretamente do solo; sempre que possível conduzir ensaios de

๑ 2007 Sociedade Brasileira de Zootecnia 
digestibilidade in vivo paralelo ao de pastejo e usar dados de digestibilidade in vitro validados por ensaios in vivo. Numa nova perspectiva, é demonstrado também que a medida de excreção fecal de $\mathrm{N}$ pode ser uma alternativa metodológica viável para estimar consumo a pasto.

Todas as metodologias para estimar consumo têm vantagens e desvantagens. Porém, um requisito comum a todas elas é a necessidade de se obter amostras de forragem representativas do que está sendo ingerido pelo animal no pasto. Isto é um problema metodológico crítico, pois a pastagem é um "ecossistema vivo" que se modifica a todo instante e a distribuição espacial da forragem no pasto é sempre heterogênea, mesmo em pastagens monoespecíficas. Além disso, não é conhecido o grau de variação da amostragem associado ao amostrador. A recomendação de um protocolo padrão e confiável de amostragem do pasto necessita, ainda, ser estabelecida.

Para concluir, não existe "o melhor método" para estimar consumo por ruminantes em pastejo. No entanto, existe aquele, ou uma combinação de procedimentos, que melhor se ajuste aos objetivos, à hipótese a ser testada, à precisão requerida e às condições estruturais disponíveis em cada experimento.

\section{Literatura citada}

AGREIL, C.; MEURET, M. An improved method for quantifying intake rate and ingestive behaviour of ruminants in diverse and variable habitats using direct observation. Small Ruminant Research, v.54, p.99-113, 2004.

ALI, H.A.M.; MAYES, R.W.; HECTOR, B.L. et al. Assessment of n-alkanes, long-chain fatty alcohols and long-chain fatty acids as diet composition markers: The concentrations of these compounds in rangeland species from Sudan. Animal Feed Science and Technology, v.121, p.257-271, 2005.

ALLDEN, W.G.; WHITTAKER, A.M. The determinants of herbage intake by grazing sheep: the interrelationship of factors influencing herbage intake and availability. Australian Journal Agricultural Research, v.21, p.755, 1970.

ALLEN, M.S.; LINTON, J.A.V. In vivo methods to measure digestibility and digestion kinetics of feed fractions in the rumen. In. RENNÓ, F.P.; SILVA, L.F.P. (Eds.) Simpósio Internacional Avanços em Técnicas de Pesquisa em Nutrição de Ruminantes, Pirassununga, 2007. Anais..., Pirassununga 2007. p. 72-89.

AROEIRA, L.J.M. Estimativas do consumo de gramíneas tropicais. In: SIMPÓSIO INTERNACIONAL DE DIGESTIBILIDADE EM RUMINANTES, 1997, Lavras. Anais... Lavras: Universidade Federal de Lavras, 1997. p.127-163.

ASTIGARRAGA, L. Técnicas para la medición del consumo de rumiantes en pastoreo. In: SIMPÓSIO SOBREAVALIA-ÇÃO DE PASTAGENS COM ANIMAIS, 2007, Maringá. Anais... Maringá: Universidade Estadual de Maringá, 1997. p.1-23.

BARTIAUX-THILL, N.; OGER, R. The indirect estimation of the digestibility in cattle of herbage from Belgian permanent pasture. Grass and Forage Science, v.41, p.269-272, 1986.

BAUMONT, R.; COHEN-SALMON, D.; PRACHE, S. et al. A mechanistic model of intake and grazing behaviour in sheep integrating sward architecture and animal decisions. Animal Feed Science and Technology, v.112, p.5-28, 2004.

BERCHIELLI, T.T.; OLIVEIRA, S.G.; GARCIA, A.V. Aplicação de técnicas para estudos de ingestão, composição da dieta e digestibilidade. Archives of Veterinary Science, v.10, p.2940, 2005.

BERCHIELLI, T.T; VEJA, A.G; REIS, R.A. Técnicas de avaliação de consumo em ruminantes: Estado da arte. In: RENNÓ, F.P.; SILVA, L.F.P. (Eds.) Simpósio Internacional Avanços em Técnicas de Pesquisa em Nutrição de Ruminantes, Pirassununga, 2007, Anais... Pirassununga, 2007. p. 305-341.

BOVAL, M.; PEYRAUD, J.L.; XANDÉ, A. et al. Evaluation d'indicateurs fécaux pour prédire la digestibilité et les quantités ingérées de Dichanthium sp par des bovins créoles. Annales de Zootechnie, v.45, p.121-134, 1996.

BOVAL, M.; ARCHIMÈDE, H.; FLEURY, J. et al. The ability of faecal nitrogen to predict digestibility for goats and sheep fed tropical herbage. Journal of Agricultural Science, v.140, p.443-450, 2003.

BRANSBY, D.I. Compromises in the design and conduct of grazing experiments. In: MARTEN, G.C. (Ed.). Grazing Research: Design, Methodology, and Analysis. Madison: CSSA Special Publication n ${ }^{\circ}$ 16, 1989. p.53-67.

BUGALHO, M.N.; DOVE, H.; KELMAN, W. et al. Plant wax alkanes and alcohols as herbivore diet composition markers. Journal of Range Management, v.57, p.259-268, 2004.

BURNS, J.C.; POND, K.R.; FISHER, D.S. Measurements of forage intake. In: FAHEY JR., G.C. (Ed.) Forage Quality, Evaluation, and Utilization, Madison: ASA, CSSA, SSSA, 1994. p. 494-532.

CANDIDO, M.J.D.; ALEXANDRINO, E.; GOMIDE, C.A.D. et al. Período de descanso, valor nutritivo e desempenho animal em pastagens de Panicum maximum cv. Mombaça sob lotação intermitente. Revista Brasileira de Zootecnia, v.34, n.5, p.1459-1467, 2005.

CARVALHO, P.C.F. A estrutura da pastagem e o comportamento ingestivo de ruminantes em pastejo. In: Jobim, C.C., Santos, G.T., Cecato, U. (Eds.). Simpósio sobre avaliação de pastagens com animais, 1, Anais... Maringá, PR. 1997. p.25-52. 1997.

CARVALHO, P.C.F.; MORAES, A. Comportamento ingestivo de ruminantes: bases para o manejo sustentável do pasto. In: Simpósio sobre Manejo Sustentável das Pastagens, Maringá. Anais... CD-ROM. 2005.

CARVALHO, P.C.F.; PRACHE, S.; DAMASCENO, J.C. O processo de pastejo: desafios da procura e apreensão da forragem pelo herbívoro. In: Penz Junior, A.M., Afonso, L.O.B.; Wassermann, G.J. (Org.). Reunião Anual da Sociedade Brasileira de Zootecnia. Anais... Porto Alegre, 1999, v.36, p. 253-268. 1999.

CARVALHO, P.C.F; RIBEIRO FILHO, H.M.N.; POLI, C.H. E.C. et al. Importância da estrutura da pastagem na ingestão e seleção de dietas pelo animal em pastejo. In: Mattos, W. R. S. (Org.). A Produção Animal na Visão dos Brasileiros. Reunião Anual da Sociedade Brasileira de Zootecnia, Piracicaba, 2001, p.853-871, 2001.

CAUDURO, G.F.; CARVALHO, P.C.F.; BARBOSA, C.M.P. $e t$ al. Fluxo de biomassa aérea em azevém anual manejado sob duas intensidades e dois métodos de pastejo. Revista Brasileira de Zootecnia, v.36, n.2, p.282-290, 2007.

CHIBNALL, A.C.; PIPER, S.H.; POLLARD, A. et al. The constitution of the primary alcohols, fatty acids and paraffins present in plant and insect waxes. Biochemistry Journal, v.28, p.2189-2208, 1934.

COLEMAN, S.W. Predicting forage intake by grazing ruminants. In: FLORIDA RUMINANT SYMPOSIUM, 2005, [S.1.: s.n]. Proceedings... 2005. p.72-90. 
COMERÓN, E.A. Estimation des quantités ingerees para des vaches laitieres au patûrage: influence des caractéristiques des animaux; influence de la quantité et de la structure de I'herbe offerte. Rennes: Université de Rennes, 1991. 156p. Tese (Doutorado) - Université de Rennes, 1991.

COMERÓN, E.A.; PEYRAUD, J.L. Predicción de la digestibilidad del pasto ingerido por vacas lecheras. Revista Argentina de Producción Animal, v.13, p.23-30, 1993.

CORBET, J.L. Measurement of forage intake of grazing animals. In: WHEELER, J.L., MOCHRIE, R.D. (Eds.). Forage Evaluation: Concepts and Techniques. Victoria: CSIRO, 1980. p.287-298.

CÔRTES, C.; DAMASCENO, J.C.; PAINE, R.C. et al. Uso de alcanos na estimativa da composição botânica em amostras com diferentes proporções de Brachiaria brizantha e Arachis pintoi. Revista Brasileira de Zootecnia, v.34, n.5, p.14681474, 2005.

CRANCIO, L.A.; CARVALHO, P.C.F. Seleção de dietas de animais pastejando ambientes pastoris complexos. Revista Científica Rural. (2007 - no prelo)

CURTIS, K.M.S.; HOLST, P.J.; MURRIA, P.J. Measuring supplement intake in the field using ytterbium as a marker. Australian Journal of Experimental Agriculture, v.34, p.339-343, 1994.

DEMARQUILLY, C.; CHENOST, M.; GIGER, S. Pertes fécales et digestibilité des aliments et des rations. In: JARRIGE, R.; RUCKEBUSCH, Y.; DEMARQUILLY, C.; FARCE, M. H.; JOURNET, M. (Ed.) Nutrition des Ruminants Domestiques. Ingestion et Digestion. Versailles: INRA Editions, 1995. p.601-647.

DITTRICH, J.R.; CARVALHO, P.C.F.; MORAES, A. et al. Comportamento ingestivo de eqüinos em pastejo sob diferentes dosséis. Ciência Animal, v.8, p.87-94, 2007.

DOVE, H. Using the n-alkanes of plant cuticular wax to estimate the species composition of herbage mixtures. Australian Journal of Agricultural Research, v.43, p.1711-1724, 1992.

DOVE, H.; MAYES, R.W. The use of plant wax alkanes as marker substances in studies of the nutrition of herbivores: a review. Australian Journal of Agricultural Research, v.42, p.913952, 1991.

DOVE, H.; MAYES, R.W. Plant wax components: a new approach to estimating intake and diet composition in herbivores. Journal of Nutrition, v.126, p.13-26, 1996.

DOVE, H.; MAYES, R.W. Satellite Meeting: Wild and Domestic Herbivore Diet Characterization. In: THE INTERNATIONAL SYMPOSIUM OF NUTRITION OF HERBIVORES, 6., 2003, Mérida. Proceedings... Mérida: UADY, 2003. p.88.

DOVE, H.; MOORE, A.D. Using a least-squares optimization procedure to estimate botanical composition based on the alkanes of plant cuticular wax. Australian Journal of Agricutural Research, v.46, p.1535-1544, 1995.

DOVE, H.; MOORE, A.D. Using a least-squares optimization procedure to estimate botanical composition based on the alkanes of plant cuticular wax. Australian Journal of Agricultural Research, v.46, p.1535-1544, 1996.

DOUGHERTY, C.T. New approaches to research at the plantanimal interface of grazing beef cattle. In: REUNIÃOANUAL DA SOCIEDADE BRASILEIRA DE ZOOTECNIA, 36. 1999, Porto Alegre. Anais... São Paulo: Sociedade Brasileira de Zootecnia/Gmosis [1999] CD-ROM.

EUCLIDES, V. P. B.; MEDEIROS, S.R. Suplementação animal em pastagens e seu impacto na utilização da pastagem. In: SIMPÓSIO SOBRE MANEJO DA PASTAGEM, 22., 2005, Piracicaba. Anais... Piracicaba: FEALQ, 2005. p. 33-70.

FONTANELI, R.S.; FONTANELI, R.S. Uso e abuso da espectroscopia no infravermelho (NIRS). In: SIMPÓSIO INTERNACIONAL AVANÇOS EM TÉCNICAS DE PESQUISA EM NUTRIÇÃO DE RUMINANTES, 2007, Pirassununga. Anais..., Pirassununga, 2007. p. 160-193.

FOX, D.G.; TEDESCHI, L.O.T.; TYLUKTI, M.E. et al. The
Cornell net carbohydrate an protein model for evaluating herd nutrition and nutrient excretion. Animal Feed Science and Technology, v. 112, p. 29-78, 2004.

FRASER, M.D.; THEOBALD, V.J.; MOORBY, J.M. Determining diet composition on complex swards using nalkanes and long-chain fatty alcohols. Ecological Applications, v.16, n.5, p.191-1910, 2006.

GARCIA, J. Consumo, parâmetros de fermentação ruminal, desempenho e rendimento de carcaça de novilhos. Tese (Doutorado em Zootecnia) - Universidade Estadual de Maringá, Maringá. 150p., 2004.

GARCIA, S.C.; HOLMES, C.W.; HODGSON, J. et al. The combinatiom of n-alkanes and ${ }^{13} \mathrm{C}$ techniques to estimate individual dry matter intakes of herbage and maize silage by grazing dairy cows. Journal of Agricutural Science, v.135, p.47-55, 2000.

GENRO, T.C.M. Estimativas de consumo em pastejo e suas relações com os parâmetros da pastagem em gramíneas tropicais. Tese (Doutorado em Zootecnia) - Universidade Federal do Rio Grande do Sul, Porto Alegre. 130p., 1999.

GENRO, T.C.M.; EUCLIDES, V.P.B.; MEDEIROS, S.R. Ingestão de matéria seca por ruminantes em pastejo. In: REUNIÃO ANUAL DA SOCIEDADE BRASILEIRA DE ZOOTECNIA, 41., 2004, Campo Grande. Anais... Campo Grande: Sociedade Brasileira de Zootecnia, 2004. p. 178-190.

GENRO, T.C.M.; PRATES, E.R.; CARDOSO, F.F. et al. Diet selection in a pasture of Panicum maximum cv. Mombaça with different stratum heights. In: INTERNATIONAL GRASSLAND CONGRESS, 10., 2005, Dublin. Proceedings... Dublin: Wageningen Academic Publishers, 2005.p.505.

GIBB, M. Animal grazing/intake terminology and definitions. In: Pasture Ecology and Animal Intake, 3, 1996, Dublin. Proceedings... 1998, p.21-37.

GONÇALVES, E.N. Comportamento ingestivo de bovinos e ovinos em pastagem nativa da Depressão Central do Rio Grande do Sul. Tese (Doutorado em Zootecnia) Universidade Federal do Rio Grande do Sul, Porto Alegre. 130p., 2007.

GONTIJO NETO, M.M.; BATISTA EUCLIDES, V.P.; DO NASCIMENTO, D. et al. Consumo e tempo de pastejo por novilhos Nelore em pastagem de capim-tanzânia sob diferentes ofertas de forragem. Revista Brasileira de Zootecnia, v.35, n.1, p.60-66, 2006.

GORDON, I.J. Animal-based techniques for grazing ecology research. Small Ruminant Research, v.16, p.203-214, 1995.

GRACE, N.D.; BODY, D.R. The possible use of long chain (C19$\mathrm{C} 32)$ fatty acids in herbage as an indigestible faecal marker. Journal Agricultural Science, v.97, n.3, p.743-745, 1981.

HAMELEERS, A; MAYES, W. The use of n-alkanes to estimate herbage intake and diet composition by dairy cows offered a perennial ryegrass/white clover mixture. Grass and Forage Science, v.53, p.164-169, 1998a.

HAMELEERS, A.; MAYES, R.W. The use of n-alkanes to estimate supplementary grass silage intake in grazing dairy cows. Journal of Agricultural Science, v. 131, p.205-209, 1998b.

HATFIELD, P.G.; ALKER, J.W.; FITZGERALD, J.A. et al. The effects of different methods of estimating fecal output on plasma cortisol, fecal output, forage intake, and weight change in free-ranging and confined wethers. Journal of Animal Science, v.71, p. 618-624, 1993.

HODGSON, J. Measurement of herbage intake and ingestive behaviour in grazing animals: an introduction. In: PENNING, P.D. (Ed.). Herbage Intake Handbook. 2.ed. Reading: The British Grassland Society, 2004. p.15-22.

JOHNSON, R.R. Reasons for forage evaluation. In: BARNES, R.F.; CLANTON, D.C.; GORDON, C.H. et al. (Eds.). Forage Quality Evaluation and Utilization, 1969, Proceedings... Nebraska, 1970. p.B/1-B/4.

JONES, R.J.; LUDLOW, M.M.; TROUGHTON, J.H. et al. 
Estimation of the proportion of $\mathrm{C}_{3}$ and $\mathrm{C}_{4}$ plant espécies in the diet of animals from the ratio of natural ${ }^{12} \mathrm{C}$ and ${ }^{13} \mathrm{C}$ isotopes in the faeces. Journal of Agricultural Science, v.92, p.91-100, 1979.

KOZLOSKI, G.V., PEREZ NETO, D., OLIVEIRA L. et al. Uso do óxido de cromo como indicador da excreção fecal de bovinos em pastejo: variação das estimativas em função do horário de amostragem. Ciência Rural, v.36, n.2, p.599-603, 2006.

KYRIAZAKIS, I. What are ruminant herbivores trying to achieve through their feeding behaviour and food intake? In: VI INTERNATIONAL SYMPOSIUM ON THE NUTRITION OF HERBIVORES, Proceedings...p.154-173. 2003.

LACA, E.A., DEMMENT, M.W. Modelling intake of a grazing ruminant in a heterogeneous environment. In INTERNATIONAL SYMPOSIUM ON VEGETATIONHERBIVORE RELATIONSHIPS. Proceedings...Academic Press, p.57-76. 1992

LACA, E.; WALLIS DE VRIES, M.F. Acoustic measurement of intake and grazing behaviour of cattle. Grass and Forage Science, v. .55, p.97-104, 2000.

LAIDLAW, A.S. Intake: assessment of current developments in sward measurement techniques. In: KEANE, M.G.; O'RIORDAN, E.G. Pasture Ecology and Animal Intake. Dublin: Teagasc, 1998. p.127-137.

LANCASTER, R.J. Estimation of digestibility of grazed pasture from faeces nitrogen. Nature, v.163, p.330-331, 1949.

LASCANO, C.E. Methodology for measurement of consumption under grazing conditions. In: RUIZ, M.E., RUIZ, S.E. Ruminant Nutrition Research: Methodological Guidelines. San Jose: Inter-American Institute for Cooperation on Agriculture, 1992. p.163-172.

LIPPKE, $\mathrm{H}$. Estimation of forage intake by ruminants on pasture. Crop Science, v. 42, p.869-872, 2002.

LOPES, F.C.F.; AROEIRA, L.J.M.; RODRIGUEZ, N.M. et al. Predição do consumo de pasto de capim-elefante (Pennisetum purpureum, Schumack) por vacas mestiças Holandês x Zebu em lactação. Revista Brasileira de Zootecnia, v.34, n.3, p.1017-1028, 2005.

LUKAS, M.; SUDEKUM, K.H.; RAVE, G. et al. Relationship between fecal crude protein concentration and diet organic matter digestibility in cattle. Journal of Animal Science, v.83, n.6, p.1332-1344, 2005.

MACHADO, C.F.; MORRIS, S.T.; HODGSON, J. et al. Effect of maize grain and herbage allowance on estimated metabolizable energy and animal performance in beef cattle finishing systems. Grass and Forage Science, v.61, p.385397, 2006.

MAYES, R.W.; DOVE, H. Measurement of dietary nutrient intake in free-ranging mammalian herbivores. Nutrient Research Reviews, v.13, p.107-138, 2000.

MAYES, R.W.; LAMB, C.S. The possible use of $n$-alkanes in herbage as indigestible faecal markers. IN: NUTRITION SOCIETY, 43., 1984, Cambridge. Proceedings... Cambridge: British Nutrition Society, 1984. p.39.

MAYES, R.W.; LAMB, C.S.; COLGROVE, P.M. The use of dosed and herbage $\mathrm{n}$-alkanes as marker for the determination of herbage intake. Journal Agricultural Science, v.107, p. 161-170, 1986.

McMENNIMAN, N.P. Methods of estimating intake of grazing animals. In: REUNIÃO ANUAL DA SOCIEDADE BRASILEIRA DE ZOOTECNIA, 34., 1997, Juiz de Fora. Anais... Juiz de Fora: Sociedade Brasileira de Zootecnia, 1997. p.133-168.

MÉLIX, C.; PEYRAUD, J.L. Utilisation de l'oxyde de chrome chez les vaches laitières pour la prévision des quantités de fèces émises. 2. Comparaison des méthodes de prélévement de fèces par voie rectale et par collecte globale (en stalle à digestibilité et sur le champ). Reproduction Nutrition Development, v.27(1B), p.217-218, 1987.

MÉLIX, C.; PEYRAUD, J.L.; VÉRITÉ, R. Utilisation de l'oxyde de chrome chez les vaches laitières pour la prévision des quantités de fèces émises. I. Etude des variations du taux de récupération et ses conséquences sur l'estimation de la digestibilité et des quantités ingérées de rations d'herbe et d'ensilage de maïs. Reproduction Nutrition Development, v.27(1 B), p.215-216, 1987.

MINSON, D.; WILSON, J.R. Prediction of intake as an element of forage quality. In: FAHEY JR., G. C. (Ed.) Forage Quality, Evaluation and Utilization. Madison: ASA, CSSA, SSSA, 1994. p. 533-563.

MIR, P.S.; KALNIN, C.M.; GARVEY, S.A. Recovery of fecal chromium used as a digestibility marker in cattle. Journal of Dairy Science, v.72, p.2549-2553, 1989.

MOORE, J.E.; SOLLENBERGER, L.E. Techniques to predict pasture intake. In: SIMPÓSIO INTERNACIONAL SOBRE PRODUÇÃO ANIMALEM PASTEJO, 1997, Viçosa. Anais... Viçosa, 1997. p.81-96.

MORENZ, M.J.F.; DA SILVA, J.F.C.; AROEIRA, L.J.M. et al. Óxido de cromo e alcanos na estimativa do consumo de forragem de vacas em lactação em condições de pastejo. Revista Brasileira de Zootecnia, v.35, n.4, p.1535-1542, 2006.

NATIONAL RESEARCH COUNCIL - NRC. Nutrient Requirements of Beef Cattle. 7.ed. Washington, D.C.: 1996.

OLIVÀN, M.; FERREIRA, L.M.M.; CELAYA, R. et al. Accuracy of the n-alkane technique for intake estimates in beef cattle using different sampling procedures and feeding levels. Livestock Science, v.106, p.28-40, 2007.

OLIVEIRA, D.E. Uso da técnica de alcanos para medir o aporte de nutrientes através de estimativas do consumo de forragem em bovinos. Tese (Doutorado em Agronomia) Escola Superior de Agricultura “Luiz de Queiroz", Piracicaba. 129p., 2003.

OLIVEIRA, D.E.; PRATES, E.R.; PERALBA, M.C.R. Identificação e quantificação de alcanos presentes nas ceras de plantas forrageiras. Revista Brasileira de Zootecnia, v.26, n.5, p.881-886, 1997.

ORÓ, J.; NOONER, D.W.; WIKSTRÖN, S.A. Paraffinic hydrocarbons in pasture plants. Science, v.147, n.3659, p.870873, 1965.

PALHANO, A.L.; CARVALHO, P.C.F.; DITTRICH, J.R. et al. Estrutura da pastagem e padrões de desfolhação em capimMombaça em diferentes alturas do dossel forrageiro. Revista Brasileira de Zootecnia, v.34, n.6, p.1860-1870, 2005.

PALIERAQUI, J.G.B.; FONTES, C.A.A.; RIBEIRO, E.G. et al. Influência da irrigação sobre a disponibilidade, a composição química, a digestibilidade e o consumo dos capins mombaça e napier. Revista Brasileira de Zootecnia, v.35, n.6, p.23812387, 2006.

PEDREIRA, C.G.S. Avanços metodológicos na avaliação de pastagens. In: REUNIÃO ANUAL DA SOCIEDADE BRASILEIRA DE ZOOTECNIA, 39., 2002, Recife. Anais... Recife: Sociedade Brasileira de Zootecnia CD-ROM.

PENNING, P.D. The European intake workshop: how far have we come since 1974? In: IX EUROPEAN INTAKE WORKSHOP, 9., 1998, North Wyke. Techniques for investigating intake and ingestive behaviour by farm animals. Proceedings... North Wyke, 1998. p.67-73.

PENNING, P.D. Animal-based techniques for estimating herbage intake. In: PENNING, P.D. (Ed.). Herbage Intake Handbook. 2ed. Reading: The British Grassland Society, 2ed. p.53-94. 2004. PENNING, P.D.; RUTTER, S.M. Ingestive behaviour. In: PENNING, P.D. (Ed.). Herbage Intake Handbook. 2ed. Reading: The British Grassland Society, 2004. p.151-175.

PEYRAUD, J.L. Techniques for measuring herbage intake of grazing ruminants: a review. In. SPÖRNDLY, E.; BURSTEDT, E.; MURPHY, M. Managing high yielding dairy cows at pasture, 1996 Uppsala. Proceedings...Uppsala: Swedish University of Agricultural Sciences, Report 243, p.3-23, 1997. PHILLIPS, C.J.C. The use of individual animals as replicates in statistical analysis of their behaviour at pasture. Applied

๑ 2007 Sociedade Brasileira de Zootecnia 
Animal Behaviour Science, v.60, p.365-369, 1998.

PIDGEN, W.; MINSON, D.J. Measuring herbage consumption of grazing animals. In: CAMPBELL, J.B. (Ed.) Experimental Methods for Evaluating Herbage. Canada: Department of Agriculture, 1969. p.152-168.

PINTO, C.E.; CARVALHO, P.C.F.; FRIZZO, A. et al. Comportamento ingestivo de novilhos em pastagem nativa do Rio Grande do Sul. Revista Brasileira de Zootecnia, v.2, p.319-327, 2007.

PITTROFF, W.; SOCA, P. Physiology and models of feeding behaviour an intake regulation in ruminants. In: BELS, V. (Ed.). Feeding in Domestic Vertebrates: from Structure to Behaviour. Oxford: CAB, 2006. p.278-302.

PONTES, L.S.; CARVALHO, P.C.F.; NABINGER, C. et al. Fluxo de biomassa em pastagens de azevém anual (Lolium multiflorumLam) manejadas em diferentes alturas. Revista Brasileira de Zootecnia, v.33, n.3, p.529-537, 2004.

PROVENZA, F.D.; VILLALBA, J.J.; HASKELL, J.W. et al. The value to herbivores of plant physical and chemical diversity in time and space. Crop Science, v.47, p.382-398, 2007.

REID, J.T. Indicator methods in herbage quality studies. In: BLASER, R.E.; CARTER, J.F.; CHAMBLEE, D.S. (Eds.). Pasture and Range Research Techniques. Ithaca: Comstock Publishing Associates, 1962. p.45-56.

RIBEIRO FILHO, H.M.N.; DELAGARDE, R.; PEYRAUD, J.L. Inclusion of white clover in strip-grazed perennial ryegrass swards: herbage intake and milk yield of dairy cows at different ages of sward regrowth. Animal Science, v.77, p.499-510, 2003.

RIBEIRO FILHO, H.M.N.; DELAGARDE, R.; PEYRAUD, J.L. Herbage intake and milk yield of dairy cows grazing perennial ryegrass swards or white clover/perennial ryegrass swards at low- and medium-herbage allowances. Animal Feed Science and Technology, v.119, p.13-27, 2005.

RODRIGUEZ, N.M. Uso de indicadores para estimativa de consumo a pasto e digestibilidade. In: REUNIÃO ANUAL DA SOCIEDADE BRASILEIRA DE ZOOTECNIA, 43., 2006, João Pessoa. Anais... João Pessoa: Sociedade Brasileira de Zootecnia, 2006. p.323-352.

ROOK, A.J. Design and sampling issues in grazing studies. In: EUROPEAN INTAKE WORKSHOP: Techniques for investigating intake and ingestive behaviour by farm animals.9., 1998, North Wyke. Proceedings... North Wyke: 1998. p.5-7

ROOK, A.J. The use of groups or individuals in the design of grazing experiments (reply to Phillips, 1998). Applied Animal Behaviour Science, v.61, p.357-358, 1999.

ROOK, A.J. Principles of foraging and grazing behaviour. In: Hopkins, A. (Ed.). Grass, its production and utilization. Blackwell Science Ltda. p.229-246. 2000.

ROOK, A.J. Statistical considerations in the design of herbage intake studies. In: PENNING, P.D. (Ed.). Herbage Intake
Handbook. 2ed. Reading: The British Grassland Society, 2004. p. 177-184.

SANTANA, M.C.A. Suplementação com diferentes níveis e fontes de energia para recria de novilhos em pastagens. Dissertação (Mestrado) - Universidade Federal de Viçosa, Viçosa. 81p., 2006.

SARMENTO, D.O.L. Comportamento ingestivo de bovinos em pastos de capim marandu submetidos a regimes de lotação contínua. Dissertação (Mestrado em Agronomia) - Escola Superior de Agricultura "Luiz de Queiroz", Piracicaba. 76p., 2003.

SENFT, R.L.; COUGHENOR, M.B.; BAILEY, D.W. et al. Large herbivore foraging and ecological hierarchies. BioScience, v.37, p.789-799, 1987.

SMITH, B.N. Natural abundance of the stable isotopes of carbon in biological systems. BioScience, v.22, p.226-231, 1972.

SOARES, J.P.G.; BERCHIELLI, T.T.; AROEIRA, L.J.M. et al. Estimativas de consumo de capim-elefante (Pennisetum purpureum Schum), fornecido picado para vacas lactantes utilizando a técnica do óxido de cromo. Revista Brasileira de Zootecnia, v.33, n.3, p.811-820, 2004.

STUEDEMANN, J.A.; MATCHES, A.G. Measurement of animal response in grazing research. In: MARTEN, G.C. (Ed.). Grazing Research: Design, Methodology, and Analysis. Madison: CSSA Special Publication n ${ }^{\circ}$ 16, 1989. p.21-36.

TRINDADE, J.K. Modificações na estrutura do pasto e no comportamento ingestivo de bovinos durante o rebaixamento do capim-Marandu submetido a estratégias de pastejo rotacionado. Dissertação (Mestrado em Ciência Animal e Pastagens) - Escola Superior de Agricultura "Luiz de Queiroz", Universidade de São Paulo, Piracicaba. 162 p., 2007.

UNGAR, E.D.; RUTTER, S.M. Classifying cattle jaw movements: comparing IGER Behaviour Recorder and acoustic techniques. Applied Animal Behaviour Science, v.98, p.11-27. 2006.

VAN SOEST, P.J. Nutritional Ecology of the Ruminant. 2ed. New York: Cornell University Press, 1994. 476p.

WANYOIKE, M.M.; HOLMES, W. A comparison of indirect methods of estimating feed intake on pasture. Grass and Forage Science, v.36, p.221-225, 1981.

WILKINS, R.J. Foreword - Herbage Intake Handbook. In: PENNING, P.D. (Ed.). Herbage Intake Handbook. 2ed. Reading: The British Grassland Society, 2004. p.13-14.

ZIMMERMANN, F. C.; RIBEIRO FILHO, H.M.N.; ZUNINO, L.G. et al. Avaliação do óxido de cromo misturado numa ração peletizada para a estimativa da produção fecal. In: REUNIÃO DA SOCIEDADE BRASILEIRA DE ZOOTECNIA, 42., 2005, Goiânia. Anais... Goiânia: Sociedade Brasileira de Zootecnia. CD ROM. 